\title{
El porvenir de una des-ilusión: Hacia un examen pluriaxial de la secularización (2)
}

\section{EXORDIO}

Tras décadas de incuestionada primacía en el seno de las ciencias sociales, ya fuera por el carácter de obviedad que se le atribuyó, o por haber sido abrazada como plataforma de pensamiento por parte de la mayoría de los padres disciplinares, la noción de secularización -y "la" teoría que le da sustento- viene enfrentando hace ya algún tiempo una serie de criticismos que apuntan no solo a su capacidad explicativa, sino también predictiva, en el marco de un conjunto de "promesas incumplidas".

Desde la "ley de los tres estadios", de un Comte (3), hasta la diferenciación funcional del subsistema religioso, de un Luhmann (4); pasando por las opiáceas facultades de la religión, acusadas por un Marx (5); los desafíos de perdurabilidad social de ciertas formas de religiosidad en contextos seculares, promulgadas por un Durkheim (6); los fenómenos de desencantamiento del mundo moderno como subproducto de los procesos de racionalización social, o las afinidades electivas entre una ética calvinista de la predestinación y el desarrollo del capitalismo, defen-

(1) Psicólogo, Máster en Ciencias Sociales (FLACSO-México), Dr.(c) en Sociología (El Colegio de México). Académico del Departamento de Psicología de la Universidad de La Serena, Matta 147, Coquimbo, Chile. EMail: fdonoso@userena.cl

(2) La preparación de este artículo fue posible gracias al financiamiento otorgado por el Fondo de Publicaciones de la Dirección de Investigación de la Universidad de La Serena (DIULS), Chile.

(3) Comte, Auguste (1855/1979). La filosofía positiva. México: Porrúa.

(4) Luhmann, Niklas (1977/1984). Religious dogmatics and the evolution of societies. Studies in Religion and Society, Vol. 9. New York: The Edwin Mellen Press.

Luhmann, Niklas (1999). Tradición y modernidad: Las relaciones entre religión y ciencia. En J. Torres (Ed.), Niklas Luhmann: Teoría de los sistemas sociales II (artículos) (pp. 149-157). Santiago: Universidad de Los Lagos/Instituto Superior de Occidente/Universidad Iberoamericana. Luhmann, Niklas (1999). Religión y sociedad. En J. Torres (Ed.), Niklas Luhmann: Teoría de los sistemas sociales II (artículos) (pp. 159-166). Santiago: Universidad de Los Lagos/Instituto Superior de Occidente/Universidad Iberoamericana.

(5) Marx, Karl (1844/1985). Manuscritos: Economía y filosofía. Madrid: Alianza Editorial.

(6) Durkheim, Emilio (1912/2000). Las formas elementales de la vida religiosa. México: Colofón. 
didos por un Weber (7); o bien, la lapidaria concepción freudiana de la religión como una ilusión infantil de dudoso porvenir (8); el hilo conductor de las explicaciones teóricas en torno al estatus social de la religión en la modernidad -al menos en occidente- ha parecido ser el mismo: la noción de pérdida de centralidad socialmente estructurante de la religión y de las instituciones religiosas, relegadas (o imperiosamente relegables) a la esfera privada, y en un nivel de considerable tensión frente a profusos procesos de laicización institucional. Diferenciación, racionalización y privatización han configurado, así, buena parte del corazón analítico de lo que se dio en denominar "teoría(s) de la secularización" (9).

Como subproducto de un racionalismo ilustrado, anclado en la prototípicamente moderna idea de progreso y de linealidad de la historia, el proyecto secularizador en el viejo continente tomó las calles y las constituciones políticas, buena parte de los centros educativos y de los planes de estudios, la resignificación y/o metamorfosis de los usos cotidianos y el enarbolamiento de ideales libertarios, mismos que, trasplantados a nuestra América morena desde mediados del siglo XVIII, llegarán a articularse a través de una nutrida gama de organizaciones coadyuvantes de las gestas independentistas y de la construcción de nuevos proyectos de sociedad (10).

Cualquiera sea nuestra evaluación de los resultados de dicho proyecto en la región, lo cierto es que la religión y las instituciones religiosas parecen preservar hoy un ostensible grado de presencia y transversalidad social. Desde expresiones altamente desinstitucionalizadas, como la religiosidad popular con su exuberante cuerpo de santos/as e íconos, hasta los recios nexos institucionales que parecen poner tope a las acepciones de diferenciación entre esferas religiosa, política y cultural; la religión pareciera seguir allí, dotando de coordenadas de sentido a nuestras "correctas" formas de nacer, vivir o morir. Es en este marco que la validez de muchos de los preceptos de las teorías de la secularización se halla en profuso debate a la luz de lo que se ha dado en denominar un "retorno de la religión a la

(7) Weber, Max (1920/2001). Ensayos sobre sociología de la religión. Tomo I. Madrid: Taurus. Weber, Max (1922/1999). Economía y sociedad. México: Fondo de Cultura Económica.

(8) Freud, Sigmund (1927/1996). El porvenir de una ilusión. En Obras Completas (Tomo III, pp. 2961-2992). Madrid: Biblioteca Nueva.

(9) Al respecto, véanse:

Berger, Peter (1994). Una gloria lejana: La búsqueda de fe en una época de credulidad. Barcelona: Herder.

Berger, Peter (2001). La désécularisation du monde: Un point de vue global. En P. Berger (Dir.), Le réenchantement du monde (pp. 13-35). Paris: Bayard Éditions.

Tschannen, Olivier (1991). The secularization paradigm: A systematization. Journal for the Scientific Study of Religion, 30(4), 395-415.

Dobbelaere, Karel (1981/1994).

Secularización: Un concepto multi-dimensional. México: Universidad Iberoamericana.

Dobbelaere, Karel (1999). Towards an integrated perspective of the processes related to the descriptive concept of secularization. Sociology of Religion, 60(3), 229-247.

(10) Bastian, Jean Pierre (1990). Historia del protestantismo en América Latina. México: CUPSA. Bastian, Jean Pierre (1995). El protestantismo en América Latina. En E. Dussel (Edit.), Resistencia y Esperanza: Historia del Pueblo Cristiano en América Latina y el Caribe (pp. 447-486). San José: DEI.

Bastian, Jean Pierre (1997). La mutación religiosa de América Latina: Para una sociología del cambio social en la modernidad periférica. México: Fondo de Cultura Económica. 
esfera pública", como fenómeno global, durante las últimas décadas (11). La gavilla de expresiones que lo anterior comporta, ha venido involucrando fenómenos tan variados como la revolución islámica iraní, la emergencia de la Teología de la Liberación en Latinoamérica, la acción de la Iglesia Católica y de "Solidaridad" en Polonia, el surgimiento de nuevas modalidades de fundamentalismo norteamericano a partir de la "New Christian Right", o los fundamentalismos islámicos de nuevo cuño, hoy banalizados bajo diversos modos, modas y medios.

$\mathrm{Si}$, desde los resabios de las premisas iluministas, un Freud se interrogó ayer acerca del "porvenir de una ilusión" (la religión), es ante el conjunto de las patentes expresiones religiosas arriba señaladas que hoy nos cuestionamos acerca del "porvenir de una des-ilusión" (secularización). Para tal empresa, en el presente trabajo nos proponemos abordar el tópico de la secularización desde diversos frentes: como concepto, (hipó)tesis, teoría, paradigma, proceso socioempírico, e incluso como dogma o acto de fe. Si bien lo anterior permite y amerita múltiples análisis desde diversas disciplinas de las ciencias sociales, en este documento nos orientaremos fundamentalmente bajo el lente de la sociología de la religión, en cuyo seno, por lo demás, se han desarrollado algunas de las más álgidas y nutridas discusiones en torno al tópico de la secularización.

\section{LA SECULARIZACIÓN COMO CONCEPTO}

En términos históricos, el concepto de "secularización" fue introducido por Longueville en las negociaciones que condujeron a la Paz de Westfalia, en 1648, aludiendo a una liquidación del poder eclesiástico en cuanto a fundaciones y posesiones. En tanto tal no tuvo, en principio, un carácter negativo, ya que en algunos casos fue promovida por la propia Iglesia; no obstante, ya hacia el siglo XIX el concepto de secularización habrá de cargarse de connotaciones de "lucha cultural" o de enfrentamiento entre los poderes eclesiales y los mundanos o seculares (12).

(11) A juicio de algunos autores, el término "retorno" no es en realidad el más adecuado, pues en muchos contextos nacionales la religión y las instituciones religiosas nunca experimentaron el supuesto declive presagiado por las teorías de la secularización. En tal sentido, fueron más bien estas últimas las que, convertidas en una suerte de fe laica, de fe en las promesas de la razón, colaboraron a generar este paisaje, requiriendo hoy de una completa reformulación a la luz de las evidencias adversas. Al respecto, véanse:

Berger, Peter (1994).

Una gloria lejana: La búsqueda de fe en una época de credulidad. Barcelona: Herder.

Berger, Peter (2001). La désécularisation du monde: Un point de vue global.

En P. Berger (Dir.), Le réenchantement du monde (pp. 13-35). Paris: Bayard Éditions.

Berger, Peter (2005). Pluralismo global y religión. Estudios Públicos, 98, 5-18.

Casanova, José (1994).

Public religions in the modern world. Chicago: The University of Chicago Press.

Robertson, Roland (1989). Globalization, politics and religion. En J. Beckford y T. Luckmann (Edits.), The changing face of religion (pp. 10-23). London: International Sociological Association/Sage.

(12) Al respecto, véanse:

Dobbelaere, Karel (1981/1994). Secularización: Un concepto multi-dimensional. México: Universidad Iberoamericana.

Mardones, José (1993). Secularización. En J. Gómez (Ed.), Religión (pp. 107-122). Madrid: Trotta. 
La posterior introducción del concepto de secularización en el Derecho Canónico tuvo por objetivo el definir la dispensa de votos religiosos. Sin embargo, además de vinculársele al ideario de la Ilustración, el concepto de secularización -o, más bien, su expresión militante bajo el rótulo de "secularismo"- llegará a ostentar diversas acepciones en distintos contextos nacionales e históricos: en la Inglaterra del siglo XIX, el término "secularismo" aparecerá relacionado a los programas de educación secular; en los Estados Unidos del siglo XX, "secularismo" hace referencia a lo "irreligioso", al "ateísmo práctico" y a la "organización de la vida como si Dios no existiese". Solo a principios del siglo XX, "secularización" emerge como una categoría "científica" o filosófico-cultural, y como tal es rastreable hasta Weber, Tönnies y Troeltsch (13).

A partir de dicho sustrato, diversas han sido las conceptualizaciones de secularización dentro de la sociología de la religión. En el marco de The Encyclopedia of Religion, editada por Mircea Eliade, el ya clásico Bryan Wilson presentará su definición en los siguientes términos: "la secularización es el proceso en el cual la conciencia, actividades e instituciones religiosas pierden importancia social. Ello indica que la religión llega a ser marginal respecto de la operación del sistema social, y que las funciones esenciales para dicha operación se tornan racionalizadas y fuera del control de las agencias orientadas a lo sobrenatural” (14).

En idéntica dirección, Cox define a la secularización como "la liberación del mundo de las interpretaciones religiosas o casi religiosas del mismo, la disipación de todas las concepciones cerradas del mundo, la destrucción de todos los mitos sobrenaturales y símbolos sagrados. Representa la "desfatalización de la historia", el descubrimiento por parte del hombre de que el mundo ha quedado en sus manos, de que ya no puede culpar a la fortuna o a las furias por lo que haga con él. La secularización tiene lugar cuando el hombre aparta la atención de los mundos del más allá para dirigirla hacia este mundo y este tiempo" (15). En efecto, "saeculum"

(13) Dobbelaere, Karel (1981/1994). Secularización: Un concepto multi-dimensional. México: Universidad Iberoamericana.

(14) Wilson, Bryan (1987). Secularization. En M. Eliade (Ed.), The encyclopedia of religion, Vol. 13 (pp. 159-165). New York: Macmillan, p. 160.

(15) Cox, Harvey (1993). Religión y política en Europa: Los nuevos debates de lo secular/sagrado y de lo público/privado. Historia y Fuente Oral, $N^{o} 10$.

Desde una perspectiva teológica, ya casi dos décadas antes Cox sostenía que esta mundanización comportada por la secularización no debía ser entendida como un alejamiento de Dios, sino, por el contrario, como una manera en que Dios se acerca al mundo del hombre. Véase, al respecto: Cox, Harvey (1975). The secular city - ten years later. The Christian Century, 28 de Mayo, 544547. Recuperado el 3 de Junio, 2005, desde http://www.religion-online.org/ showarticle .asp?title $=1861$

En este mismo sentido, Vattimo ha planteado la idea de una "secularización positiva" sustentada en la noción de kenosis; es decir, en el "abajamiento de Dios", patente ya en su pacto con Israel, y luego en la encarnación de Cristo. Según dicho autor, se trataría de una secularización actual que invita a sustituir la metafísica noción de Dios como juez, absoluto, omnipotente, trascendente, frente al cual solo nos queda definirnos como siervos, por otra de carácter postmetafísico que nos habla de un Dios cercano frente al cual podemos definirnos como amigos, y que en tanto tal constituye el núcleo del mensaje de salvación cristiano. Véase: Vattimo, Gianni (1996). Creer que se cree. Barcelona: Paidós.

Sin duda, estas concepciones apuntan en la misma dirección que las observaciones ya realizadas por Jung en torno al cambio dramático representado por el paso desde el Dios severo, castigador 
significa "la época presente", cuyo enfrentamiento habrá de estructurar lo que Bonhoffer designó como "la mayoría de edad del hombre" (16).

Un intento serio -aunque, a nuestro juicio, deficiente- de abordaje del concepto de secularización, y que amerita suficiente detención, es el desarrollado en el hoy ya clásico estudio de Dobbelaere, bajo la asunción de que se trata de un "concepto multidimensional" (17). Así, dicho autor inicia su trabajo criticando la parcialidad y confusiones en torno a las diversas acepciones teóricas del concepto de secularización, como subproductos inevitables de los enfoques que la propia sociología de la religión ha adoptado evolutivamente en el curso de su desarrollo como disciplina: "la mayoría de los sociólogos de la religión divide la historia de su especialidad en tres períodos: un período clásico, dominado por Durkheim y Weber; un período intermedio de sociología denominacional o de iglesia, inspirado por una mala interpretación de Le Bras; y un período neoclásico, que se caracteriza por un retorno a las fuentes de la sociología de la religión, y que se centra, citando a Luckmann, en "el problema de la existencia personal en la sociedad, que es esencialmente una cuestión de la forma social de la religión"” (18). A juicio del autor, desarrollos de esta naturaleza derivaron muchas veces en estudios empíricos sobre la participación en denominaciones, que constituyeron básicamente investigaciones de integración normativa; esto es, estudios que midieron la conformidad entre las normas de comunidades religiosas -en los campos de la creencia, ritual y ética- y el conocimiento, actitudes y conductas de sus miembros. Ello redundó en el análisis de la relevancia de las iglesias para los individuos, pero no de su relevancia social. Adicionalmente, ello implicó un deterioro de los desarrollos teóricos, hipotecados en función de una estrecha orientación metodológica de corte positivista, y, lo más importante, en una errada y simplificada identificación unidimensional de la secularización con los procesos de (descenso en la) participación religiosa.

Tras la revisión de una amplia gama de teorías, Dobbelaere plantea que el concepto de secularización puede ser descompuesto en tres dimensiones que, a su juicio, deben ser mantenidas analíticamente separadas a fin de evitar los errores disciplinares del pasado:

1) Secularización como un proceso de laicización: Que alude a las relaciones religión-sociedad. "La laicización hace referencia a un proceso de diferenciación: se desarrollan instituciones que realizan diferentes funciones y son estructuralmente diferentes. La religión se convierte en una institución junto con otras instituciones y pierde su pretensión globalizante... lo que supone que la sociedad, gradualmente, asume todas las funciones seculares previamente desarrolladas por la religión" (19). Esta transformación del ámbito sagrado en

y discrecional del Antiguo Testamento, a un Dios de amor del Nuevo Testamento, anunciado por -y encarnado en- Jesús. Al respecto, véase: Jung, Carl Gustav (1952/1998). Respuesta a Job. Madrid: Fondo de Cultura Económica de España.

(16) Cox, Harvey (1993). Religión y política en Europa: Los nuevos debates de lo secular/sagrado y de lo público/privado. Historia y Fuente Oral, $N^{\circ} 10$.

(17) Dobbelaere, Karel (1981/1994). Secularización: Un concepto multi-dimensional. México: Universidad Iberoamericana.

(18) Ibíd., p. 3.

(19) Ibíd., p. 8. 
instituciones seculares implica una desacralización del mundo (o "desencantamiento del mundo", en términos weberianos), cuyo dominio está basado ahora en la tecnología y el cálculo, en lugar de la magia (racionalización de las esferas institucionales). En este mismo sentido, la secularización como proceso de laicización se refiere "a la decreciente relevancia de los valores, institucionalizados en la religión orientada hacia la iglesia, para la integración y legitimación de la vida cotidiana en la sociedad moderna" (20).

La secularización, desde esta acepción laicizante, puede ser descrita tanto como un proceso latente o como un resultado de política deliberada o manifiesta (ej.: Durkheim y la laicización escolar en Francia). Particularmente en este último caso, resulta también factible el surgimiento de contrapolíticas o expresiones manifiestas de antilaicización por parte de algunas iglesias.

2) Secularización como proceso de cambio religioso: Que se refiere a la relación religión-religión. "El cambio religioso expresa el cambio que ocurre en la postura de organizaciones religiosas -iglesias, denominaciones y sectas- en materia de creencias, moralidades y rituales, y supone también un estudio del descenso y surgimiento de grupos religiosos. Este es el tipo de "secularización" que Shiner llamó "adecuación con "este mundo"” (21).

Elementos de gran importancia, aquí, son los impactos de la laicización sobre la capacidad de adaptación de las iglesias, lo que a juicio de algunos autores ha implicado el despliegue de una serie de fenómenos y estrategias no exentas de un tinte de "mercado religioso": pluralismo, competitividad, burocratización, profesionalización, racionalización, ingeniería organizacional, etc. (22).

3) Secularización como un proceso de descenso de la participación religiosa: Que alude a la relación individuo-institución religiosa. De acuerdo a Dobbelaere, este punto "hace referencia al comportamiento individual y mide el grado de integración en corporaciones religiosas. Es un índice de la articulación entre las normas de grupos religiosos y la conducta y actitudes de sus miembros" (23).

El problema con Dobbelaere, a nuestro juicio, es que este autor no logra articular o integrar satisfactoriamente estas diversas dimensiones del concepto de seculari-

(20) Ibíd., p. 4.

(21) Ibíd., p. 8.

(22) Al respecto, véanse:

Berger, Peter (1973). Para una teoría sociológica de la religión. Barcelona: Kairós.

Berger, Peter (1997). Epistemological modesty: An interview with Peter Berger.

The Christian Century, 29 de Octubre, 972-978. Recuperado el 10 de Junio, 2003, desde http:// www.religion-online.org/cgi-bin/relsearchd.dll/showarticle?item_id=240

Bourdieu, Pierre (1994/2002). Razones prácticas. Barcelona: Anagrama.

Gill, Anthony (1994). Rendering unto Caesar?: Religious competition and Church-State relations in Latin America, 1930-1979. Tesis de Doctorado en Ciencia Política, University of California, Los Angeles. Ann Arbor: University Microfilms International (UMI).

Iannaccone, Laurence; Finke, Roger y Stark, Rodney (1997). Deregulating religion: The economics of church and State. Economic Inquiry, 35(2), 350-364.

Stark, Rodney y Bainbridge, William (1985). The future of religion: Secularization, revival and cult formation. Los Angeles: University of California Press.

(23) Dobbelaere, Karel (1981/1994). Secularización: Un concepto multi-dimensional. México: Universidad Iberoamericana, p. 8. 
zación (24). En efecto, la salida que él intenta para todas aquellas situaciones en que las tres dimensiones del concepto de secularización no resultan estar alineadas es una salida en el ámbito conceptual, pero que no explica lo que sucede en el plano empírico: si la situación a analizar se refiere a una sociedad en que existe alta diferenciación entre religión y política (lo cual resultaría confirmatorio de secularización vía laicización), pero donde también existe una alta asistencia de sus habitantes a las iglesias (desconfirmatorio), Dobbelaere se remitirá simplemente a señalar que no podemos fiarnos de una sola expresión, pues de hacerlo se estarían confundiendo los planos o dimensiones del concepto. Es decir, en el mejor de los casos, el autor nos diría que tal sociedad se presenta como secularizada en una dimensión, mas no en la otra, con lo cual no logra aportarnos una respuesta mínimamente integral para efectos de comprender cómo se articulan esas consonancias y/o disonancias.

Con todo, de lo anteriormente enunciado podemos colegir que, a partir del sustrato histórico que le dio pie, el concepto de secularización pasa a ser apropiado y desarrollado disciplinariamente en el seno de la sociología (entre otras ciencias sociales) bajo los auspicios de un encargo ideológico epocal que hubo de mantenerse hasta buena parte del siglo XX: la noción subyacente de que la religión está condenada a la pérdida de centralidad social (en su versión más suave), o incluso a su extinción (en la más severa, particularmente hasta los años 60), y que su vehículo y sepulturero estará constituido por un proceso lineal, progresivo e irreversible, denominado secularización. Esta noción parece no ser privativa de un sesgo positivista encarnado por algunos padres de la disciplina, como Comte o Spencer, sino que también puede encontrarse en los "maestros de la sospecha" (Marx, Nietzsche o Freud), que en muchos sentidos resultan directa o tangencialmente cercanos a una orientación hermenéutica.

\section{LA SECULARIZACIÓN COMO (HIPÓ)TESIS}

Si acaso puede hablarse de una "tesis" o "hipótesis" de la secularización, esta atañe a la postulación de su inherente vinculación con la tesis de la modernidad (25). Ya sea como hermanas o madres mutuas, modernidad y secularización fueron habitualmente planteadas como procesos recíprocos, deambulando por marcos conceptuales comunes en los que se funden, separan y confunden una y otra vez. Desde esta perspectiva, se asume que no podría entenderse el nacimiento del mundo mo-

(24) A ello debiéramos agregar nuestras reservas respecto de la originalidad de esta tridimensionalización elaborada por Dobbelaere, por cuanto resulta ser cuasi idéntica a la desarrollada ya una década antes por Scharf, Betty (1974). El estudio sociológico de la religión. Barcelona: Seix Barral.

(25) Aunque no hemos de profundizar aquí en su tratamiento diferencial, explicitamos la necesaria distinción señalada por García Canclini -con base en Habermas y en Berman- entre "la modernidad como etapa histórica, la modernización como proceso socioeconómico que trata de ir construyendo la modernidad, y los modernismos, o sea los proyectos culturales que renuevan las prácticas simbólicas con un sentido experimental o crítico”. Al respecto, véase: García Canclini, Néstor (1989/2002). Culturas híbridas: Estrategias para entrar y salir de la modernidad. México: Grijalbo, p. 19. 
derno prescindiendo de los procesos de secularización, o viceversa (26). Es por ello que la secularización muchas veces pasará a ser concebida como una suerte de indicador moderno: el avance de la secularización constituirá una muestra fehaciente del avance de la modernidad.

En tanto tesis, la secularización habrá de sustentarse en una noción lineal de la historia, como una expresión más del moderno ideal de progreso. Como ya fue acusado, su expresión militante será el "secularismo", que habrá de vaticinar toda clase de defunciones para la religión y los símbolos sagrados (27). No obstante, en tanto tal, la tesis de la secularización parecerá correr la misma suerte de aquello que Brunner ha conceptuado como el "falso dilema" modernidad versus tradicionalismo, donde este último estaba supuestamente confinado a desaparecer tras el avance inclaudicable de la modernidad (28). Sobra subrayar que dicho enfoque no solo no logró vislumbrar la posibilidad de coexistencia entre mundos moderno y tradicional, sino que además construyó una serie de mitos en torno a la modernidad, que llegaron incluso a ostentar modalidades de sacralización secular. Acaso el ejemplo de la sacralización de la política (y particularmente del Estado-nación) hasta buena parte del siglo XX, no constituya sino una expresión paradigmática al respecto (29).

Es en razón de esta supuesta relación inextricable y mutuamente retroalimentada entre modernidad y secularización, que las críticas a la primera han también alcanzado a la segunda, llevando a plantear el fracaso teórico y analítico-conceptual de ambas, a caballo del prefijo "post": un fracaso de la modernidad esgrimido por/ desde la postmodernidad, a la par que lo propio para la secularización, encarnado por lo que algunos han dado en denominar "postsecularización"; es decir, una "secularización de la secularización” (30). Desde esta perspectiva, según Mardones "la postsecularización supone tanto un fenómeno de redescubrimiento de lo religioso, como de distanciamiento y distorsión. Lo sagrado aparece hoy como ambiguo, ambi-

(26) Werblowsky, Zwi (1981). Más allá de la tradición y la modernidad: Religiones cambiantes en un mundo cambiante. México: Fondo de Cultura Económica.

(27) Mardones, José (1996). ¿Hacia dónde va la religión?: Postmodernidad y postsecularización. Cuadernos de Fe y Cultura, No. 1. México: Universidad Iberoamericana/ITESO.

(28) Brunner, José Joaquín (1992). La libertad de los modernos: Una visión desde la sociología. Estudios Públicos, 46, 43-93.

(29) A juicio de Lechner, en muchos sentidos los siglos XIX y XX fueron testigos de cómo la política llegó a ocupar el lugar sacro dejado por la religión tras la secularización religiosa. No obstante, y como fenómeno ya patente hacia fines del siglo XX, será el colapso de la pretensión de la política en cuanto a otorgar una síntesis convincente y holística de la sociedad -tal como lo ha subrayado Luhmann-, lo que permitirá hablar actualmente de una verdadera "secularización de la política", o, parafraseando a Weber, de un "desencantamiento de la política". Al respecto, véanse:

Lechner, Norbert (1995). Los patios interiores de la democracia. Santiago: Fondo de Cultura Económica.

Luhmann, Niklas (1981/1993).

Teoría política en el Estado de Bienestar. Madrid: Alianza Editorial.

Luhmann, Niklas (1984/1998). Sistemas sociales: Lineamientos para una teoría general. Barcelona: Anthropos/Universidad Iberoamericana/CEJA, Pontificia Universidad Javeriana.

(30) Al respecto, véanse:

Martelli, Stefano (1999). Ni secularización ni desacralización, más bien desecularización; la teoría sociológica de la religión ante el cambio actual. Religiones y Sociedad, 7, 153-167.

Mardones, José (1996). ¿Hacia dónde va la religión?: Postmodernidad y postsecularización. Cuadernos de Fe y Cultura, No. 1. México: Universidad Iberoamericana/ITESO. 
valente y múltiple. No recorre un solo sendero, en la dirección de las religiones institucionalizadas, sino que prolifera a la vera de esos caminos más consagrados y en manifestaciones más o menos inesperadas. Tiene el carácter de algo abierto y hasta versátil y desestructurado. Es un redescubrimiento de lo sagrado que, no se puede olvidar, aparece en un cuadro de crisis social y cultural generalizada. De aquí que adopte la forma no de la superación de la secularización en todos los puntos, ni siquiera de una religiosización o reencantamiento lógicamente planificado y desarrollado, sino de manifestaciones múltiples, desinstitucionalizadas, libres, temporales, cambiantes, eclécticas, fragmentadas. El "pastiche", que Jameson pone como característica del arte y la cultura postmoderna, también tiene su aplicación a la religiosidad postmoderna" (31).

No obstante lo anterior, la sustitución de la vieja ecuación modernidad = secularización por la de postmodernidad = postsecularización - que no hace sino reproducir una misma lógica- ciertamente no constituye el aguijón más relevante de este debate (32). Ello, particularmente si se considera que tras décadas de vaticinios cuasi apocalípticos, el propio discurso postmoderno ha devenido otro metarrelato, enfrentando un inevitable desgaste que ha llevado hoy incluso a algunos de quienes fueran sus más fervorosos párrocos, como Lipovetsky, a renegar de sus "exageraciones de juventud" (33). Acaso el problema radique en que, tal como ha planteado Wolfart (34), los proponentes de la postmodernidad no hacen sino reproducir, a partir de la modernidad, lo que ya los humanistas del Renacimiento o

(31) Ibíd., p. 41.

(32) Prueba suficiente de ello nos la otorga una "teología postmoderna" que, ya hacia los 80 , tendrá por desafío central la búsqueda de cómo estructurar un discurso que, siendo aún teológico, se resista a pasar a un plano metafísico que, en tanto tal, implicaría la confluencia de una ontoteología, de una metafísica de la presencia y de un logocentrismo. Al respecto, véase Westphal, Merold (1997). Postmodern theology. En E. Craig (Ed.), Routledge encyclopedia of philosophy (pp. 583-586). New York: Routledge.

Bajo tal norte, algunas de las principales expresiones de esta teología postmoderna abordaron tópicos no exentos de considerables desafíos analíticos. Así, por una parte, encontramos la discusión acerca de si la deconstrucción derrideana constituye o no una modalidad de "teología negativa" (en la acepción de Eckhart), como fundamento de una teología postmetafísica. Al respecto, véase Hart, Kevin (1989). The trespass of the sign: Deconstruction, theology and philosophy. Chicago: University of Chicago Press. Por otra parte, resulta factible observar la búsqueda de nuevas posibilidades de significados religiosos mediante la deconstrucción crítica de conceptos fundamentales dentro de la tradición judeocristiana (como los de "Dios", "alma" o "historia"), tal como lo intenta la "a/teología" de Taylor, Mark (1984). Erring: A postmodern a/theology. Chicago: University of Chicago Press. En este mismo marco, acaso tampoco resulten meritorios de olvido los esfuerzos de un Marion por liberar el discurso teológico de todas las teorías filosóficas del ser -incluido el análisis postmoderno del ser de Heidegger-, como modo de superar la constitución ontoteológica de la metafísica. Al respecto, véase Marion, Jean-Luc (1982). God without being. Chicago: University of Chicago Press.

(33) Apostando hoy por la idea de una "hipermodernidad", que implicaría una exacerbación de las manifestaciones de la modernidad, Lipovetsky afirmará: “...la noción de sociedad posmoderna es falsa. Nunca existió la sociedad posmoderna. Fue una palabra, que yo también empleé, pero no es grave. Tuvo éxito porque estuvo ligada a la idea de que uno se escaparía de algo que era como una prisión; era algo jubilatorio, pero en realidad, como label (marca), es un label falso.". Véase: Lipovetsky, Gilles (2004, 15 de Agosto). "Nunca existió la sociedad posmoderna". El Mercurio, pp. E12-E13, específicamente, p. E13.

(34) Wolfart, Johannes (2000). Postmodernism. En W. Braun y R. McCutcheon (Eds.), Guide to the study of religion (pp. 380-395). London: Cassell. 
los racionalistas del Iluminismo hicieron en su momento: definir/construir/inventar/imaginar una era anterior -bajo el siempre dudoso procedimiento de presentarla como categoría discreta- respecto de la cual diferenciarse, asumiéndola como superada (la oscuridad de la Edad Media, y la ignorancia y superstición preiluministas, respectivamente). En tanto tal, la noción de postmodernidad continúa anclada a una concepción de progresión desde una época a otra en términos lineales, teleológicos o, incluso, escatológicos, apoyada en una correlativa pandemia del prefijo "post" como elemento de caracterización generalizada del contexto social, político, económico y cultural, cuando menos, del primer mundo (postindustrial, postcapitalista, postestructural, postmaterialista, postmarxista, postfordista, postdemocrático, postsocial, etc.).

Si bien, a juicio de Wolfart (35), esta lógica de progresión postmoderna paradójicamente refuerza la idea de linealidad del iluminismo moderno -distanciándose con ello de una cíclica concepción renacentista que asumía un "re-nacimiento" o retorno de una época anterior, más que la inauguración de una nueva-, lo cierto es que son no pocos los criticismos que tienden a identificar a la noción de postmodernidad con formas de "retorno", ya sea como expresión de un neoconservadurismo político (36), o de un conformismo sociopolítico derivado de la ausencia de un proyecto de futuro (37).

(35) Ibíd

(36) Como es sabido, un caso emblemático a este respecto lo encontramos en Habermas, quien rotula a la línea de pensamiento francés de la postmodernidad como "neoconservadora" debido a la refractariedad de esta a asumir al menos un estándar libre de una crítica autorreferencial totalizadora para efectos de llevar adelante un proyecto de desenmascaramiento de todos los demás estándares razonables, en tanto fundamento de una crítica teórica-racional de las instituciones existentes. Véase, al respecto, Habermas, Jurgen (1989). Modernidad: Un proyecto incompleto". En N. Casullo (Comp.), El debate modernidad postmodernidad (pp. 131-144). Buenos Aires: Punto Sur Editores.

No obstante, según Rorty, "Desde el punto de vista de Lyotard, Habermas está ofreciendo una metanarrativa más, una 'narrativa de la emancipación' más general y abstracta que las metanarrativas freudiana y marxista", pero metanarrativa al fin, frente a la cual -como ya es sabido del estilo de Lyotard- solo cabe la incredulidad. Véanse, al respecto:

Rorty, Richard (1999). Habermas y Lyotard sobre la posmodernidad. En R. Bernstein (Comp.), Habermas y la modernidad (pp. 253-276). Madrid: Cátedra, p. 254.

Lyotard, Jean-François (1979/1998). La condición postmoderna. Madrid: Cátedra.

Bajo una crítica simultánea a la modernidad y a la postmodernidad, Touraine también hará alusión al carácter políticamente conservador de esta última, ya sintomáticamente esgrimido bajo las condiciones históricas y sociopolíticas de su surgimiento: "la idea de revolución, como lo dije desde el comienzo, siempre estuvo estrechamente relacionada con la de modernidad. El éxito intelectual del postmodernismo fue, a fines de la década de 1970, una consecuencia directa de la crisis del izquierdismo revolucionario. El neoliberalismo, que triunfa en la vida económica y política durante la década de 1980 , y el posmodernismo cultural son productos paralelos de la descomposición del izquierdismo, forma extrema de modernismo... En Francia, es Jean Baudrillard quien realiza con mayor determinación este paso desde la crítica izquierdista a la crítica posmodernista del izquierdismo y hasta la negación de lo social.". Al respecto, véase Touraine, Alain (2000). Crítica de la modernidad. México: Fondo de Cultura Económica, p. 187.

(37) Al respecto, véase Lechner, Norbert. (1995). Los patios interiores de la democracia. Santiago: Fondo de Cultura Económica; y la crítica particularmente ácida a la noción de postmodernidad, proferida por Wilson, Bryan (1998). The secularization thesis: Criticisms and rebuttals. En R. Laermans, B. Wilson \& J. Billiet (Edits.), Secularization and Social Integration (pp. 45-65). Louvain: Leuven University Press. 
De esta manera, ya sea en el seno de esta noción de retorno, o bien a partir del desmantelamiento de las pretensiones secularizantes de la modernidad, la llamada postmodernidad se presentaría como un marco eventualmente auspicioso para la religión y los agentes religiosos (no es Dios el que ha muerto, sino la moderna fe en la razón), al propio tiempo que amenazante para la secularización y los agentes de laicización institucional (la idea de una "laicidad amenazada"), bajo la paradigmática asunción de un "retorno de la religión a la esfera pública", de la cual, supuestamente, había sido desalojada.

Más allá de lo hasta aquí expuesto, acaso sean los modernos y/o postmodernos elogios de la pluralización (cultural, religiosa, política, moral, estética, etc.) los que mayores tensiones y desafíos sociopolíticos y sociorreligiosos auguran (38). En efecto, inserta en el corazón de los debates entre liberalismo y comunitarismo -en el seno del creciente multiculturalismo de las sociedades actuales-, esta pluralización -y su correlativo relativismo- aboga por una apertura de los patrones de legitimidad hacia las más diversas expresiones culturales, dotadas de una pletórica agenda de procesos de lucha por reconocimiento (39). En este sentido, como ya muchos han anotado, ciertas entidades religiosas no habrán de diferenciarse demasiado de algunas minorías étnicas en sus denuncias ante organismos internacionales para efectos de reclamar la legitimidad de sus aspiraciones y expresiones, trasladando el problema de la secularización y laicidad a una verdadera arena de debate sobre multiculturalismo; cuestión que, en algunos casos, efectivamente involucra una yuxtaposición entre dimensiones religiosas y étnicas, como lo demuestra, por ejemplo, el caso de los musulmanes en Europa (40). Lo relevante y complejo de este tipo de situación es que, en dicha clase de litigios, las entidades religiosas invocan para sí los mismos preceptos de tolerancia, libertad e igualdad que el Estado laico dice defender y cautelar, obligándolo, por tanto, a dar muestras públicas de consistencia.

Con todo, se hace patente que la vinculación modernidad-secularización ha resultado empíricamente decepcionante y analíticamente nefasta, situación que no parece encontrar remedio mediante la adición de la cada vez más dudosa y deshilachada categoría de "postmodernidad". ¿Qué nos prometía la secularización y qué/ cuánto de ello se cumplió? ¿Resiste la secularización, como quiera que se la conciba (concepto, hipótesis, teoría, paradigma, etc.), un mínimo análisis falsacionista?

(38) Véanse:

Berger, Peter (1997). El pluralismo y la dialéctica de la incertidumbre. Estudios Públicos, 67, 118 .

Berger, Peter (2005). Pluralismo global y religión. Estudios Públicos, 98, 5-18.

(39) Al respecto, véanse:

Taylor, Charles (1994). La ética de la autenticidad. Barcelona: Paidós.

Taylor, Charles (2001). El multiculturalismo y "la política del reconocimiento". México: Fondo de Cultura Económica.

Kymlicka, Will (1996). Ciudadanía multicultural: Una teoría liberal de los derechos de las minorías. Barcelona: Paidós.

(40) Véanse:

Bader, Veit (1999). Religious pluralism: Secularism or priority for democracy? Political Theory, 27(5), 597-633.

Haarscher, Guy (2002). El laicismo. Santiago: Ediciones del Instituto Laico de Estudios Contemporáneos (ILEC). 
Todo intento serio de respuesta debiera sustentarse en la consideración de, al menos, algunos de los más renombrados esfuerzos de teorización en torno a la secularización, a la luz de ciertos referentes empíricos; ambos, aspectos que pasaremos consecutivamente a revisar.

\section{LA SECULARIZACIÓN COMO TEORÍA}

La articulación teórica del supuesto proceso de declive religioso a nivel social e individual, como concepción convencional de la secularización, ha sido habitualmente tipificada bajo el rótulo de "Teoría de la Secularización". Aunque parezca paradójico, "entre los partidarios más fervorosos de esta teoría se encuentran teólogos, muchos de los cuales -durante un siglo como mínimo- han tomado como punto de partida la suposición no sometida a examen según la cual el hombre moderno es un personaje inevitable e irreversiblemente secularizado, debiendo la teología ajustarse a este supuesto hecho" (41).

No obstante, la usual pretensión de hablar de "La Teoría de la Secularización" -como si realmente existiese (o hubiera existido) una tal teoría particular claramente formulada, sistematizada y/o suficientemente confirmada por determinados autores(42) no pasa de ser una abstracción cuando se considera la larga serie de propuestas explicativas sobre el fenómeno. Lo correcto, por ende, es hablar de "teorías" (en plural) de la secularización, sin omitir a sus respectivos autores, tal como puede apreciarse -muy esquemáticamente- en la siguiente "galería de clásicos" elaborada a partir de la sistematización de Tschannen (43).

\section{Autor Teoría de la Secularización}

Thomas Luckmann El fenómeno de la secularización se inicia con la diferenciación a nivel de la conciencia, cuando la originalmente homogénea visión de mundo se divide en distintas capas o niveles, las más elevadas de las cuales llegan a orientarse hacia los aspectos más problemáticos de la existencia humana. Este nuevo nivel de conciencia superordinadamente diferenciado

(41) Berger, Peter (1994). Una gloria lejana: La búsqueda de fe en una época de credulidad. Barcelona: Herder, p. 39. Ello dio pie, dentro del cristianismo estadounidense de la segunda mitad del siglo XX, a lo que se consignó como “Teología Radical”. Calificada por Berger (1994) como "una imbecilidad de corta vida, promocionada por los medios de comunicación", esta vertiente teológica hubo de explayarse en torno a la necesidad de edificar una teología secular, augurando un escaso futuro para el cristianismo en tanto no se renunciara a la idea de un Dios sobrenatural, incompatible con una era secular de la ciencia, en donde el concepto de trascendencia se ha perdido. Al respecto, ver Hamilton, van Buren y Altizer, en el trabajo de Ogletree, Thomas (1968). Controversia sobre "la muerte de Dios". Barcelona: Kairós. Para la versión europea de esta discusión, véase Borne, Guitton, Ricoeur y Schwartz (1968). Dios, hoy. Barcelona: Kairós.

(42) Crítica persistentemente esgrimida por Casanova, José (1994). Public religions in the modern world. Chicago: The University of Chicago Press.

(43) Tschannen, Olivier (1991). The secularization paradigm: A systematization. Journal for the Scientific Study of Religion, 30(4), 395-415. 
(religión) da pie, entonces, a una base social diferenciada (instituciones religiosas). A partir de esta transformación, surgen varias consecuencias:

1) La religión pierde su poder de control sobre otras esferas de la vida, las cuales comienzan a funcionar autónomamente.

2) Surge una pluralidad de visiones de mundo, mutuamente incompatibles y en competencia, que lleva a la interpretación religiosa del mundo a perder plausibilidad y a colapsar.

3) La consecuencia más importante es el surgimiento de los procesos de privatización: en el contexto de los puntos 1) y 2), el individuo debe construir su propia (privatizada) visión de mundo tomando libremente ciertos elementos provenientes de las diversas visiones de mundo en competencia. Esta privatización tiene 2 corolarios: a) Por una parte, los temas religiosos surgidos en esta esfera privada (tales como la "autonomía individual") llegan a generalizarse y comienzan a funcionar como elementos de una nueva religión, una religión "invisible". b) Por otra parte, esta religión privatizada llega a ser cada vez más mundana en la medida en que se vincula crecientemente con las "pequeñas trascendencias de la vida cotidiana" (por ejemplo, en los "cultos de la unidad").

\section{Peter Berger}

Esta es una teoría un tanto más ambigua: La secularización es el resultado de diversas causas, entre las que se destacan la emergencia del monoteísmo, del protestantismo y de la industria moderna. Más aún, no siempre resulta claro si los factores primarios están situados en el dominio de las ideas o en la estructura social. Sin embargo, desde una perspectiva diacrónica estas ambigüedades resultan menos visibles: La secularización posee raíces religiosas, ya que se inicia con los procesos de racionalización religiosa que tuvo lugar en el antiguo judaísmo. Los procesos de diferenciación también juegan cierto rol aquí: por ej., a través de la emergencia de un Dios trascendente, como prototipo de la separación entre "este mundo" y el "otro mundo", que se materializó en la Edad Media con la estructuración de la Iglesia como institución. No obstante, la principal vía de la secularización continúa siendo la racionalización (tanto en la religión como en la industria moderna), la cual ha conducido a la autonomización de la sociedad respecto del control religioso. En un "nivel objetivo", esta autonomización se manifiesta como una pluralización de las organizaciones religiosas (que ya no pueden imponer sus productos, sino que deben tratar de "venderlos" dentro de un mercado competitivo); y en un "nivel subjetivo", como 
Bryan Wilson

\section{David Martin}

un colapso de la visión de mundo. Más aún, la pluralización conduce a una creciente mundanización de las diferentes denominaciones, ya que todas ellas deben adoptar las mismas estructuras burocráticas en la lucha por la sobrevivencia en el aludido mercado competitivo.

Aquí pareciéramos encontrar la más completa de las teorías en revisión, pero también la menos sistemática. Wilson rechaza el establecimiento de una secuencia rígida de eventos y propone, en cambio, una serie de conceptos y análisis factibles de ser aplicados en distintas situaciones históricas. Así, esta teoría señala que, desde los más primigenios estadios de la historia de la civilización occidental, la secularización ocurre en el contexto de una larga transición global desde la "comunidad" a la "sociedad" (en el sentido propuesto por Tönnies). La fuerza más importante en este contexto general es la racionalización, la cual es a la vez causa y uno de los productos de la secularización. La racionalización se manifiesta primariamente como una transformación del control social, el cual pierde su sustento moral para transformarse en un control técnico y anónimo. Por otra parte, la racionalización también se manifiesta en la creciente burocratización de las interacciones sociales. Fenómenos colaterales resultan ser la diferenciación de la religión respecto de otros roles e instituciones, la autonomización de la sociedad respecto de la tutela religiosa, el auge de la ciencia y la sociología en tanto nuevas explicaciones del mundo, la pluralización de la religión y la creciene mundanización de sus organizaciones, el declive de la práctica y afiliación religiosas y el incremento del ateísmo a nivel individual.

Esta teoría es muy distinta de las anteriores en cuanto a sus propósitos. Martin no analiza el proceso global de la secularización, que a su juicio ya ha sido desarrollado de manera aceptable por otros autores. Su propósito es refinar la teoría y demostrar que la secularización no es un proceso lineal, sino que tiene distintas consecuencias en diferentes sociedades. Así, el resultado de la secularización será muy distinto de acuerdo al grado de pluralismo en un país determinado. Por ejemplo, en un país basado en un monopolio católico, como Francia, la secularización redundará en una polarización y radicalización sobre ambos lados del ámbito religioso, al propio tiempo que surgirá una profunda división política sobre la religión. En el otro extremo, en un país pluralista, como Estados Unidos, la religión nunca llegará realmente a ser un tema político, evidenciándose una ausencia de la aludida división. 


\section{Richard Fenn}

Talcott Parsons

Robert Bellah
Estas diferentes situaciones están también relacionadas con el grado de diferenciación entre Estado y religión.

Nos hallamos aquí frente a una teoría que rechaza los escenarios esgrimidos por las anteriores, para centrarse en la idea de que debemos evitar definir a la religión de una manera simple y considerar, en cambio, que la secularización constituye precisamente una batalla librada en la sociedad en un sentido amplio sobre la definición de la religión o, en otras palabras, sobre las fronteras de lo sacro. Así, el proceso de la secularización es una batalla entre los actores sociales que desean expandir el dominio de "lo sacro" y aquellos que desean restringirlo. El proceso resultante de esta lucha puede ser resumido en cinco pasos, que no forman una secuencia evolutiva, sino que admiten flujos reversos. El primer paso es la emergencia del clero: una vez que una categoría especializada de actores sociales ha establecido una relación particular con lo sacro, la batalla en torno a la definición de las fronteras de lo sacro (paso 2) se inicia. En el paso 3, el Estado contesta y demanda compartir la autoridad social detentada por lo sacro, promoviendo, así, una religión civil. La batalla continúa, con un creciente número de participantes, a través del paso 4, hasta alcanzar consecuencias finales, como por ejemplo, la separación entre las esferas individual y colectiva que hoy presenciamos (paso 5).

Se trata de una teoría bastante parcial y, de hecho, no fue originalmente designada como una "teoría de la secularización". Subraya de manera explícita dos movimientos complementarios: la privatización de la religión y su generalización. La estratificación social genera la necesidad de legitimaciones para la desigualdad. La religión constituye una de tales modalidades de legitimación. Así, la diferenciación estructural da pie e incrementa la diferenciación cultural, la cual, a su vez, conduce inevitablemente al pluralismo. A partir de allí, la privatización y la generalización surgen de manera mecánica: la primera, porque el individuo debe establecer qué religión quiere elegir; y la segunda, porque es necesario un sistema de valores unificados, por sobre aquellos propuestos por las religiones fragmentadas, si la sociedad quiere permanecer integrada.

Comparte con la teoría de Parsons su carácter parcial y la idea -aunque de manera más bien implícita- de complementariedad entre privatización y generalización. No obstante, a diferencia de dicho autor, Bellah plantea que la 
diferenciación original no se ubica en la estructura social, sino en el propio sistema simbólico, lo que la hace más complicada, evolucionando hacia una estructura "infinitamente múltiple”. Los vínculos entre la privatización resultante de esta fragmentación y la emergencia de la religión civil (generalización) no están explícitamente planteados en los trabajos de Bellah.

Exentos de todo ánimo de una clasificación exhaustiva, a esta sistematización de Tschannen debemos agregar a lo menos otros tres aportes teóricos de relevancia:

- "Peter Berger II": Bajo esta denominación nos referimos a la inflexión teórica experimentada durante esta última década por Berger, expresada en su visión de quiebre de la vieja afinidad establecida entre modernidad y secularización: según él, la modernidad no necesariamente conduce a la secularización (entendida como el declive de la religión, tanto en la sociedad como en la mente de los individuos), careciendo, por tanto, de utilidad analítica para explicarla (44). A juicio del autor, el ejemplo emblemático es Estados Unidos, altamente moderno y, no obstante, de fuerte vitalidad religiosa. Los casos de otros países, de limitada modernización y, sin embargo, también alta explosión religiosa, no vendrían sino a confirmar lo anterior. Dicha vitalidad religiosa llevará a Berger no solo a reconocer lo que él considera como limitaciones o "errores" de sus teorizaciones previas, sino a asumir la idea de una "desecularización del mundo".

Según Berger, a lo que la modernidad y la modernización sí parecen conducir -en virtud de los procesos de urbanización, escolarización, migración, etc., por ellas comportados-, es a una pluralización social, cultural, religiosa, étnica, etc., que llega a operar una ruptura de monopolios de significados, abriendo paso a ineludibles dosis de relativismo. Lo anterior, si bien mina una serie de certezas (tradicionales) tenidas por dadas, no necesariamente genera efectos secularizantes: se puede vivir creyendo seriamente en ellas aun cuando ya no ostenten su status original.

Por otra parte, Berger ha adelantado un punto que ha sido objeto de fuerte revisionismo hasta por los más enérgicos defensores de "la Teoría de la Secularización": el sesgo eurocéntrico de la modernidad (45) posee su correlato en

(44) Véase, por ejemplo:

Berger, Peter (1994). Una gloria lejana: La búsqueda de fe en una época de credulidad. Barcelona: Herder.

Berger, Peter (1997). Epistemological modesty: An interview with Peter Berger. The Christian Century, 29 de Octubre, 972-978. Recuperado el 10 de junio, 2003, desde http://www.religiononline.org/cgi-bin/relsearchd.dll/showarticle?item_id=240

Berger, Peter (2001). La désécularisation du monde: Un point de vue global. En P. Berger (Dir.), Le réenchantement du monde (pp. 13-35). Paris: Bayard Éditions.

Berger, Peter (2005). Pluralismo global y religión. Estudios Públicos, 98, 5-18.

(45) Sesgo que, por cierto, ha sido ampliamente denunciado, entre otros, por Eisenstadt, Shmuel (2002). The civilizations of the Americas: The crystallization of distinct modernities. Comparative sociology, 1(1), 43-61; y por Touraine, Alain (2000). Crítica de la modernidad. México: Fondo de Cultura Económica. 
una "Teoría de la Secularización” también eurocéntrica, obligando a su reconsideración. De allí que Berger afirme que, en realidad, la teoría de la secularización sí ha funcionado, pero para un punto específico del globo, cual es Europa occidental ("la isla secularizada"). A ella se agrega otro "territorio" en el que la teoría de la secularización también se confirma: el segmento de intelectuales de distintos puntos del globo que, en función de su formación y campos de especialización, comparten una visión secularizada del mundo.

Las asunciones de este giro de Berger no han estado exentas de críticas y/o relativizaciones, como las encarnadas por Mason, quien sostiene que "los mayores movimientos de secularización en la historia humana poseen raíces religiosas y ocurrieron antes de la era moderna. La secularización, entonces, no tiene una relación intrínseca con la modernización. Sin embargo, el caso inverso no es válido: La modernización, al menos en algunas versiones, tiene una tendencia intrínseca a generar procesos de secularización” (46). Según Mason, más allá del hecho de que existan varias modernidades en distintas naciones, ni siquiera en Europa resulta factible observar una correlación temporal entre modernidad y secularización, pues los efectos secularizadores de la primera son siempre tardíos. Ello sugeriría la necesidad de modificaciones teóricas que permitan identificar los elementos que interfieren, obstaculizan o retrasan dichos efectos, o bien, el asumir que hay otras influencias o eventuales subproductos de la modernización no presentes en sus etapas iniciales.

- Rodney Stark: De justicia será el señalar que Stark y sus colaboradores no enarbolan una teoría de la secularización de manera profusa y sistemática (de hecho, su conceptualización de la misma es extraordinariamente simple y amplia). No obstante, los incluimos aquí por distintas razones: en parte, porque constituyen una referencia cada vez más frecuente en la sociología de la religión; por su aplicación sistemática de una peculiar clase de sustrato teórico, cual es la del rational choice, que no ha dejado de resultar refractaria para buena parte de los sociólogos de la religión, particularmente de los europeos; $y$, fundamentalmente, porque ofrecen una visión muy distinta de la secularización (y de la religión), desidentificándola de los procesos de modernización.

Si bien algunos esbozos de la concepción de mercado religioso en sociología de la religión pueden ser advertidos ya en Bourdieu (47) y Berger (48), será con Stark y una serie de sus seguidores (49) que dicha noción, ampliada y

(46) Mason, Michael (2002, Julio). Secularisation is alive and well- and living in Australia. Paper presented at the World Congress of Sociology; Brisbane, Australia, p. 5.

(47) Bourdieu, Pierre (1971). Génesis y estructura del campo religioso. Revue francaise de sociologie, Vol. XII/Traducción FLACSO-Argentina, documento no publicado.

(48) Berger, Peter (1973). Para una teoría sociológica de la religión. Barcelona: Kairós.

(49) Véanse, por ejemplo:

Finke, Roger; Guest, Avery y Stark, Rodney (1996). Mobilizing local religious markets: Religious pluralism in the Empire State, 1855 to 1865 .

American Sociological Review, 61 (2), 203-218.

Finke, Roger y Stark, Rodney (1988). Religious economies as sacred canopies: Religious mobilization in American cities, 1906. American Sociological Review, 53(1), 41-49. 
profundizada bajo el concepto de "economía religiosa", alcanzará un desarrollo extremo, no exento, por cierto, de gran polémica (50). Con todo, el impacto de este enfoque sobre la disciplina -particularmente en Estados Unidos- ha sido de tal magnitud, que hace ya más de una década Warner llegó a calificarlo como "un nuevo paradigma en la sociología de la religión" (51).

En este marco, y bajo una orientación claramente utilitarista y conductista, Stark y Bainbridge definen a la religión como "un sistema de compensadores muy generales basados sobre asunciones sobrenaturales" (52). Las dos premisas en que se sustenta tal definición, son: 1) que los seres humanos, en todo tiempo y lugar, han buscado y buscan obtener recompensas y evitar castigos; y 2) que las recompensas suelen ser escasas y, más aún, que hay ciertas clases de recompensas que no pueden obtenerse sobre la base de fuentes naturales (léase "de este mundo"), sino sobrenaturales, como la vida después de la muerte. Desde este punto de vista, la "demanda" por religión ha sido y será una constante en la historia de la humanidad; no así "la oferta religiosa", que estará supeditada a aspectos tales como la regulación del mercado religioso (fundamentalmente por parte del Estado y del marco jurídico institucional, sin perjuicio de otras regulaciones de carácter informal y/o discrecional), condicionando

Finke, Roger y Stark, Rodney (1989). Evaluating the evidence: Religious economies and sacred canopies. American Sociological Review, 54(6), 1054-1056.

Finke, Roger y Stark, Rodney (1992). The churching of America: Winners and losers in our religious economy. New Brunswick: Rutgers University Press.

Iannaccone, Laurence (1994). Why strict churches are strong.

American Journal of Sociology, 99(5), 1180-1211.

Iannaccone, Laurence; Finke, Roger y Stark, Rodney (1997). Deregulating religion: The economics of church and State. Economic Inquiry, 35(2), 350-364.

Stark, Rodney y Bainbridge, William (1985). The future of religion: Secularization, revival and cult formation. Los Angeles: University of California Press.

(50) Para un abordaje de algunas de las más relevantes y ácidas críticas a este modelo, véanse:

Bankston III, Carl (2003). Rationality, choice, and the religious economy: Individual and collective rationality in supply and demand. Review of Religious Research, 45(2), 155-171.

Bruce, Steve (1992). Pluralism and religious vitality. En S. Bruce (Ed.), Religion and modernization: Sociologists and historians debate the secularization thesis (pp. 170-194). Oxford: Clarendon Press.

Bruce, Steve (2006). Les limites du "marché religieux". Social Compass 53(1), 33-48.

Chaves, Mark y Gorski, Philip (2001). Religious pluralism and religious participation. Annual Review of Sociology, 27, 261-281.

Hak, Durk (2007). Stark and Finke or Durkheim on conversion and (re-)affiliation: An outline of a structural functionalist rebuttal to Stark and Finke. Social Compass, 54(2), 295-312.

Jerolmack, Colin y Porpora, Douglas (2004). Religion, rationality, and experience: A response to the new rational choice theory of religion.

Sociological Theory, 22(1), 140-160.

Olson, Daniel (1998). Religious pluralism in contemporary U.S. counties. American Sociological Review, 63(5), 759-761.

Pace, Enzo (2006). Salvation goods, the gift economy and charismatic concern. Social Compass 53(1), 49-64.

Stolz, Jörg (2006). Salvation goods and religious markets: Integrating rational choice and Weberian perspectives. Social Compass 53(1), 13-32.

(51) Warner, Stephen, (1993). Work in progress toward a new paradigm for the sociological study of religion in the United States. American Journal of Sociology, 98(5), 1044-1093.

(52) Stark, Rodney y Bainbridge, William (1985). The future of religion: Secularization, revival and cult formation. Los Angeles: University of California Press, p. 432. 
con ello el nivel de pluralismo religioso en un determinado país y/o época. En este sentido, este enfoque postula que el grado de vigor religioso debe buscarse no en la demanda (como lo han hecho hasta aquí los enfoques clásicos), sino en la oferta religiosa. De ahí que estos autores aludan a su teoría bajo el rótulo de "supply-side" (53), constituyendo justamente este un crucial punto de debate: mientras para Stark et al. el pluralismo conduce a una mayor competitividad religiosa, incrementando el nivel de religiosidad y vinculación de las personas a las iglesias; para autores europeos, como Bruce (54) o Pace (55), lo anterior solo resulta posible en Estados Unidos, donde opera un mercado religioso abierto, libre y competitivo, mas no en los países del viejo continente, en los que históricamente ha primado el monopolio de una determinada iglesia. Por otra parte, a juicio de estos últimos autores, el pluralismo religioso no generaría mayor vitalidad religiosa, sino, todo lo contrario, mayores niveles de tolerancia y, por ende, de secularización (56).

Con todo, Stark et al. asumen que la religión jamás desaparecerá, pues detenta el monopolio de dotación de los aludidos compensadores sobrenaturales. Lo que sí puede ocurrir es que las viejas tradiciones religiosas sucumban cuando

(53) Véanse, por ejemplo:

Finke, Roger y Stark, Rodney (1992). The churching of America: Winners and losers in our religious economy. New Brunswick: Rutgers University Press.

Finke, Roger y Stark, Rodney (1998).

Reply to Olson: Religious choice and competition.

American Sociological Review, 63(5), 761-766.

Iannaccone, Laurence; Finke, Roger y Stark, Rodney (1997). Deregulating religion: The economics of church and State.

Economic Inquiry, 35(2), 350-364.

(54) Bruce, Steve (1992). Pluralism and religious vitality. En S. Bruce (Ed.), Religion and modernization: Sociologists and historians debate the secularization thesis (pp. 170-194). Oxford: Clarendon Press.

Bruce, Steve (2006). Les limites du "marché religieux". Social Compass 53(1), 33-48.

(55) Pace, Enzo (2006). Salvation goods, the gift economy and charismatic concern. Social Compass 53(1), 49-64.

(56) En idéntica dirección, véanse los planteamientos de Halman, Loek y Draulans, Veerle (2006). How secular is Europe? The British Journal of Sociology, 57(2), 263-288.

Más allá de los casos norteamericano y europeo, para una aplicación del modelo de "economía religiosa" a América Latina, véanse:

Gill, Anthony (1999). Government regulation, social anomia and protestant growth in Latin America. Rationality and Society, 11(3), 287-316.

Gill, Anthony (1999). The struggle to be soul provider: Catholic responses to protestant growth in Latin America. En Ch. Smith y J. Prokopy (Eds.), Latin American religion in motion (pp. 17-42). New York: Routledge.

Gill, Anthony (1999). The economics of evangelization. En P. Sigmund (Ed.), Religious freedom and evangelization in Latin America: The challenge of religious pluralism (pp. 70-84). New York: Orbis Books.

Chesnut, Andrew (2003). A preferential option for the spirit: The Catholic charismatic renewal in Latin America s new religious economy. Latin American Politics and Society, 45(1), 55-85.

De manera particular, para un análisis comparativo de la mayor competitividad del mercado religioso en Chile que en Argentina, hipotéticamente debido a las menores regulaciones de dicho mercado en el primer país, véase Gill, Anthony (1994). Rendering unto Caesar?: Religious competition and Church-State relations in Latin America, 1930-1979. Tesis de Doctorado en Ciencia Política, University of California, Los Angeles. Ann Arbor: University Microfilms International (UMI). 
han alcanzado niveles demasiado altos de racionalización; es decir, se han vuelto empresas más de este mundo que del más allá, lo que hace que pierdan su antigua capacidad de otorgar tales compensadores (57). En tal caso, dichas viejas tradiciones serán indefectiblemente reemplazadas por la emergencia de nuevas religiones (que en sus inicios siempre ostentarán un carácter obscuro) y, en tanto tal, esta emergencia será a la vez un síntoma de descenso de las ya establecidas.

Bajo estos supuestos, y asumiendo la noción de que lo secular alude a lo perteneciente a "este mundo", Stark y Bainbridge definen a la secularización como "la dinámica primaria de las economías religiosas: un proceso autolimitado que genera reavivamientos (formación de sectas) e innovación (formación de cultos)" (58). Desde esta perspectiva, "la secularización no constituye un fenómeno nuevo, sino algo que está ocurriendo constantemente en todas las economías religiosas. A través de la secularización, las sectas son transformadas en iglesias. Su inicial orientación al más allá es reducida y su orientación a este mundo es acomodada" (59). Es por ello que estos autores expresarán sus reservas respecto de uno de los supuestos subyacentes a "la" teoría de la secularización: "la mayoría de los autores, no obstante, no considera las actuales tendencias de la secularización como la plataforma del cambio religioso, sino como el ocaso final de los dioses" (60).

Planteamientos como estos nos recuerdan -utilizando la terminología de Vergara- la ya vieja asunción según la cual el metodismo representó un (re)avivamiento en el seno de la Iglesia Anglicana ("segunda reforma"), situación que más tarde resultará recursiva cuando el pentecostalismo haga lo propio al interior del metodismo, al "constatar" que este último "se había enfriado" ("tercera reforma") (61). No obstante, se trata de un modelo competitivo entre organizaciones religiosas, de tipo culto-cliente (como los propios autores lo señalan); es decir, sustentado en una lógica bastante moderna de mercado religioso, no necesariamente válida para procesos y momentos históricos en que la adscripción religiosa no era elegida, sino prescripta. Al propio tiempo, la férrea lógica que une a cada una de sus proposiciones bien puede llegar a constituir su mayor limitación a la hora de abordar segmentos

(57) Enfatizando este rol de la diferenciación social, en conjunción con la competencia entre organizaciones religiosas, Phillips utilizará el rótulo de "neosecularización" para abordar el caso específico de Estados Unidos, caracterizado por una fuerte separación entre esferas religiosa, política, jurídica, etc., y, no obstante, una alta asistencia de la población a cultos religiosos. Así, Phillips afirmará que es justamente en la medida en que las iglesias se concentran en aspectos religiosos, y no de otra índole (diferenciación), que los devotos habrán de identificar a estas como "el” lugar para conectarse con Dios y con una esfera sobrenatural.Al respecto, véase Phillips, Rick (2004). Can rising rates of church participation be a consequence of secularization? Sociology of Religion, 65(2), 139-153.

(58) Stark, Rodney y Bainbridge, William (1985). The future of religion: Secularization, revival and cult formation. Los Angeles: University of California Press, pp. 429-430.

(59) Ibíd., p.429.

(60) Ibíd., p. 430.

(61) Vergara, Ignacio (1962). El protestantismo en Chile. Santiago: Editorial del Pacífico. 
de la vida religiosa que escapan a dimensiones propias de una racionalidad utilitarista (62).

Tal vez el punto más interesante de este enfoque, para los fines del presente trabajo, es que aquí la secularización no requiere de la modernidad: se la plantea como un ineludible fenómeno de tensión entre este mundo y el del más allá, en cuyo núcleo las diversas tradiciones y organizaciones religiosas deben aprender a navegar para efectos de asegurar su supervivencia. No se trataría, por tanto, de un fenómeno de época, sino de una dinámica de cambio inherente a la naturaleza de los propios fenómenos e instituciones religiosos.

- Niklas Luhmann: La secularización, de acuerdo con Luhmann, es una consecuencia de la diferenciación funcional de la sociedad. Ello ocurre cuando el sistema religioso ya no logra presentarse al individuo primariamente como "la" sociedad, sino como un subsistema social más, orientado hacia un dominio específico, tal como ocurre con otros subsistemas, como la economía, la política, la ciencia, etc. (63).

De acuerdo a nuestro autor, en todo sistema diferenciado y autorreferencial se dan tres tipos de relaciones sistémicas: 1) la relación con la sociedad (función), 2) las relaciones con otros subsistemas (servicios auxiliares), y 3) las relaciones consigo mismo (autorreflexión) (64). Estas relaciones han generado, respectivamente, tres grandes áreas de especialización funcional al interior de las religiones cristianas, las cuales han sido denominadas por Luhmann como la función espiritual (Iglesia), la función auxiliar (diakonía) y la dogmática religiosa (o teología) (65). Operando sobre la base de la distinción binaria entre lo determinado y lo indeterminado, la función espiritual hace factible las "reducciones última y fundamental de la complejidad", resolviendo contingencias. La religión ofrece, así, leyes fundamentales para la vida social y hace sentido de las situaciones aparentemente sin sentido, tales como la muerte, las coincidencias históricas y las irregularidades de la naturaleza y de la motivación humana (66).

Según Luhmann, el problema central de esta función espiritual en una sociedad secularizada es que los motivos de los participantes privados ya no son controlados por medio de la membresía eclesial. La iglesia se ha adaptado a esto y

(62) Así, algunas extrapolaciones extremas desde la esfera económica a la religiosa, desarrolladas en este modelo, muchas veces habrán de exhibir un cariz más bien forzado que convincente, como parecen mostrarlo Iannaccone, Finke y Stark cuando -sustentados en las observaciones de Adam Smith sobre la religión- afirman que el libre mercado en la religión, al igual que el libre mercado de otros bienes, incrementa la eficiencia de los oferentes y, con ello, los niveles de consumo religioso. Véase, al respecto:

Iannaccone, Laurence; Finke, Roger y Stark, Rodney (1997). Deregulating religion: The economics of church and State. Economic Inquiry, 35(2), 350-364.

(63) Luhmann, Niklas (1977/1984). Religious dogmatics and the evolution of societies. Studies in Religion and Society, Vol. 9. New York: The Edwin Mellen Press.

(64) Luhmann, Niklas (1984/1998). Sistemas sociales: Lineamientos para una teoría general. Barcelona: Anthropos/Universidad Iberoamericana/CEJA, Pontificia Universidad Javeriana.

(65) Luhmann, Niklas (1977/1984). Religious dogmatics and the evolution of societies. Studies in Religion and Society, Vol. 9. New York: The Edwin Mellen Press.

(66) Ibíd. 
puede ofrecer alternativas, pero debe percatarse de que los resultados de sus actividades estarán determinados por las contingencias de la vida privada de la gente. Las dificultades surgen en el sentido de que la comunicación espiritual es inútilmente ofrecida y de que los miembros de la Iglesia son marginales en la sociedad; al mismo tiempo, los demás subsistemas -economía, política, educación y ciencia- no estimulan a la gente a ir a la iglesia, y la esfera privada se encuentra fragmentada a niveles tales que impiden a la religión la posibilidad de realizar una síntesis convincente de la vida social. Lo anterior, a juicio de Luhmann, conduce a que la función espiritual pierda considerable terreno frente a las funciones auxiliares (ej.: beneficencia, educación, etc., que, por lo demás, se hallan cada vez más adaptadas a las necesidades de los clientes/ usuarios), lo cual genera problemas de sentido, puesto que es la función espiritual la que le da identidad al sistema religioso. Al final, el carácter religioso de las funciones auxiliares estará reducido a "la disposición de hacer algo" (por el prójimo). Con todo, y como uno de los más importantes resultados de la secularización, la relativa pérdida de la función espiritual de la Iglesia se verá compensada por su mayor actividad social (67).

Valga advertir que lo aquí expuesto se desprende de lo que podría conceptuarse como el primer período productivo de Luhmann en torno al tópico de la religión, fundamentalmente desarrollado a partir de su obra Funktion der religion, de 1977 (68), y que le ha valido su identificación con la fórmula "secularización = diferenciación funcional". "El Luhmann tardío sobre religión" (69) -por cierto más complejo, aunque confirmatorio de su trabajo previo en relación al problema de la secularización- habrá de incorporar la noción de autopoiesis de la comunicación religiosa, así como la articulación de la distinción determinado/indeterminado con la noción de unidad en la diferencia de la "forma" religiosa que delimita la función de la religión en tanto operación de distinción sobre el código binario inmanencia/trascendencia (70), privilegiando el lente de esta última: "una comunicación es, entonces, siempre religiosa cuando ella observa la inmanencia desde el punto de vista de la trascendencia... Solo cuando son vistos desde la trascendencia, los eventos de este mundo adquieren un significado religioso" (71).

(67) Dobbelaere, Karel (1981/1994). Secularización: Un concepto multi-dimensional. México: Universidad Iberoamericana.

(68) Brevemente comentada por Beyer, Peter (1984). Introduction. En N. Luhmann, Religious dogmatics and the evolution of societies. Studies in Religion and Society, Vol. 9 (pp. V-LIII). New York: The Edwin Mellen Press.

(69) Véase Laermans, Rudi y Verschraegen, Gert (2001). "The late Niklas Luhmann" on religion: An overview. Social Compass, 48(1), 7-20.

(70) Por ejemplo, véase:

Luhmann, Niklas (1999b). Religión y sociedad. En J. Torres (Ed.), Niklas Luhmann: Teoría de los sistemas sociales II (artículos) (pp. 159-166). Santiago: Universidad de Los Lagos/Instituto Superior de Occidente/Universidad Iberoamericana.

Luhmann, Niklas (1999c). La distinción: Dios. En J. Torres (Ed.), Niklas Luhmann: Teoría de los sistemas sociales II (artículos) (pp. 167-188). Santiago: Universidad de Los Lagos/Instituto Superior de Occidente/Universidad Iberoamericana.

(71) Luhmann, citado en Laermans, Rudi y Verschraegen, Gert (2001). "The late Niklas Luhmann" on religion: An overview. Social Compass, 48(1), 7-20, p. 15. 
De este mosaico de contribuciones teóricas, los trabajos de Martin, Luhmann y Berger nos parecen de particular relevancia, aun cuando, en muchos aspectos, resulten mutuamente incompatibles. A nuestro juicio, y muy brevemente, el aporte de Martin destaca por su hincapié en la necesidad de contextualizar los procesos de secularización de acuerdo a la realidad sociohistórica de cada país, de donde deriva la relevancia de factores tales como la presencia de monopolios versus pluralismos religiosos, las modalidades históricas de relación de la(s) iglesia(s) con el poder político (72), etc.

Por su parte, la teoría de Luhmann permite incorporar los debates sobre la secularización y la relación religión/sociedad en un marco de teorización de extraordinaria amplitud y complejidad respecto de los procesos de diferenciación funcional de la sociedad. Más allá de las ineludibles pretensiones universalistas de tal esfuerzo -que en este aspecto lo colocan en abierta discrepancia con el aporte de Martin-, el enfoque de Luhmann nos invita a (re)pensar la autoproducción de la religión en tanto subsistema social, sin por ello dejar de desplegar nuestras legítimas inquietudes en torno a cuáles son las fronteras entre códigos religiosos y de otro tipo (por ejemplo, políticos), y de si basta la mera apelación a una diferenciación funcional para explicarlas.

Finalmente, creemos que el trabajo de Berger resulta ser de relevancia desde varios ángulos. En primer término, por su flexibilidad teórica, que le permitirá "corregir" lo que, a su juicio, constituyó su inicial y "errada" adhesión a la noción convencional de secularización (como sinónimo de declive de la religión a nivel social e individual), para pasar a asumir, a la luz de ciertas evidencias empíricas, el carácter de excepción y no de regla que tal noción entraña respecto de la realidad contemporánea (73). En segundo lugar, este autor protagonizará algunas puntualizaciones pioneras, tales como la afirmación -contraria a lo que se creía bajo el imperio de las teorías de la secularización de los 60 y 70- de que es la Europa secularizada, y no el religioso Estados Unidos, la que encarna una situación de excepción (74). Igualmente pioneros resultarán sus planteamientos en torno a la idea de mercado religioso, con iglesias que compiten por engrosar las filas de sus feligresías, coadyuvando a dar pie a lo que hoy constituye uno de los más activos y polémicos cuerpos teóricos sobre la materia (75). Finalmente, Berger ha desarrollado aportes sustantivos y pioneros en torno al rol de la pluralización religiosa y sus relaciones con los procesos de globalización, los fenóme-

(72) En este plano, por ejemplo, Martin analiza ciertas especificidades relevantes que no dejan de encontrar una caja de resonancia en nuestros países latinoamericanos, como las registradas fundamentalmente bajo regímenes autoritarios, en donde toda expresión pública proveniente de iglesias adictas al gobierno serán apaciblemente toleradas, en tanto que aquellas que procedan de iglesias reconocidamente opositoras al mismo serán tachadas de indebidas injerencias religiosas en asuntos públicos y/o políticos. Al respecto, véase Martin, David (1978/1993). A general theory of secularization. Hampshire: Gregg Revivals.

(73) Berger, Peter (1997). Epistemological modesty: An interview with Peter Berger. The Christian Century, 29 de Octubre, 972-978. Recuperado el 10 de Junio, 2003, desde http://www.religiononline.org/cgi-bin/relsearchd.dll/showarticle?item_id=240

(74) Berger, Peter (1997). El pluralismo y la dialéctica de la incertidumbre. Estudios Públicos, 67, 1-18. Berger, Peter (2001). La désécularisation du monde: Un point de vue global. En P. Berger (Dir.), Le réenchantement du monde (pp. 13-35). Paris: Bayard Éditions.

(75) Berger, Peter (1973). Para una teoría sociológica de la religión. Barcelona: Kairós. 
nos de relativismo, y la emergencia de fundamentalismos de diverso cuño, que vienen, a su juicio, a confirmar la idea de una desecularización (76).

Con todo, de lo hasta aquí exiguamente revisado, no parece exagerado afirmar que el grado de complejidad comportado por el tópico de la secularización resulta ser directamente proporcional a la cantidad de teorías esgrimidas para intentar dar cuenta del mismo. Dicha pluralización teórica -que, como habrá sido notado, ineludiblemente reditúa en conceptualizaciones diversas de la secularización- no solo complejiza el paisaje de acentos explicativos, sino que -por razones lógicas- hace imposible emitir un juicio acerca del grado de vitalidad o agonía de "la" teoría de la secularización. Aun así, si algunos puntos de relevancia podemos colegir de esta diversidad de teorías, estos aluden a una paulatina moderación de los presagios secularizantes desarrollados hasta los 60; la necesidad de localización nacional e histórico-institucional de las teorías, donde la distinción entre los casos norteamericano y europeo parece ocupar un lugar prominente; y el carácter crucial asignado a los procesos de diferenciación, racionalización y pluralización religiosa, donde esta última ha dado pie a un agudo debate en torno a su efecto secularizante versus vitalizante de la religión. Es justamente en virtud de estos y otros puntos comunes a las diversas teorías que, bajo el concepto de paradigma, se hace más factible el evaluar el estado de salud actual de los postulados de la secularización.

\section{LA SECULARIZACIÓN COMO PARADIGMA}

A juicio de algunos autores, resulta factible hablar de la existencia de un verdadero "paradigma de la secularización" (77). Casanova ha ido incluso más lejos al señalar que las ideas desarrolladas en torno a la noción de secularización llegaron a ostentar un nivel de tal centralidad en el análisis sociológico del siglo XX, que han configurado uno de los pocos marcos analíticos prístinamente tipificables en calidad de "paradigmas" dentro de la historia de la sociología como disciplina. Más aún, dicho autor sostiene que es justamente en función de lo anterior que las actuales dificultades experimentadas por las diversas teorías de la secularización, o del paradigma de la secularización, debieran entenderse -aludiendo a la jerga kuhnianacomo verdaderas "crisis", "revoluciones", y sustentos para un auténtico cambio de paradigma (78).

Como es sabido, en su clásica obra, Kuhn apuntó varias definiciones para el concepto de paradigma (79). Una que, a nuestro juicio, resulta lo suficientemente

(76) Berger, Peter (1994). Una gloria lejana: La búsqueda de fe en una época de credulidad. Barcelona: Herder.

Berger, Peter (2005). Pluralismo global y religión. Estudios Públicos, 98, 5-18.

(77) Véanse, por ejemplo:

Casanova, José (1994). Public religions in the modern world. Chicago: The University of Chicago Press.

Tschannen, Olivier (1991). The secularization paradigm: A systematization. Journal for the Scientific Study of Religion, 30(4), 395-415.

(78) Ibíd.

(79) Kuhn, Thomas (1962/2000). La estructura de las revoluciones científicas. México: Fondo de Cultura Económica. 
sintética de la noción kuhniana, es la presentada por Ritzer, para quien "un paradigma es una imagen básica del objeto de una ciencia. Sirve para definir lo que debe estudiarse, las preguntas que es necesario responder, cómo deben responderse y qué reglas es preciso seguir para interpretar las respuestas obtenidas. El paradigma es la unidad más general de consenso dentro de una ciencia y sirve para diferenciar una comunidad científica (o subcomunidad) de otra. Subsume, define e interrelaciona los ejemplares, las teorías y los métodos e instrumentos disponibles" (80). Además, señala Ritzer, "Las teorías son solo parte de paradigmas más amplios. Dicho de otro modo, un paradigma puede abarcar dos o más teorías, así como distintas imágenes del objeto, los métodos (e instrumentos) y los ejemplares (obras específicas de trabajo científico que constituyen modelos para todos los que lo siguen)" (81).

Con todo, la importancia de la propuesta kuhniana no descansa en la mera definición de qué es un paradigma, sino en la dinámica que signa los cambios de paradigmas en el tiempo. Si bien Kuhn admite que la acumulación de conocimiento juega cierto rol de relevancia en el avance de la ciencia, su afirmación de fondo es que los principales cambios son resultado de las revoluciones científicas. Como es sabido, ello implica lo siguiente: la ciencia está siempre dominada por un paradigma específico. En dicho marco, la "ciencia normal" consiste en un período de acumulación de conocimientos, en el que los científicos trabajan para extender el paradigma dominante. Dicho trabajo científico inevitablemente habrá de generar "anomalías" o hallazgos imposibles de explicar mediante tal paradigma dominante. Si estas anomalías aumentan, se produce una etapa de "crisis" que puede desembocar en una revolución científica. En tal caso, el paradigma dominante se abandona y se reemplaza por otro nuevo que ocupa su lugar en el núcleo de la ciencia. Nace, así, un nuevo paradigma dominante, repitiéndose nuevamente el ciclo.

Las legítimas preguntas que surgen aquí, son: ¿cuáles son las características del tal "paradigma de la secularización" en las ciencias sociales?, y ¿en cuál de las aludidas etapas se encuentra este actualmente?

Reservaremos la respuesta a la segunda de estas interrogantes para nuestra sección final de discusiones, mientras que, para efectos de contestar a la primera de ellas, pasaremos a revisar el intento más sistemático de explicitación de un "paradigma de la secularización" de que tengamos noticia, cuya autoría descansa en Tschannen (82). Según este autor, más allá de sus divergencias, las teorías de la secularización desarrolladas por diversos sociólogos en los 60 y 70 comparten un cierto set de asunciones y de categorías analíticas. El objetivo de Tschannen, por tanto, es el de sistematizar este marco común, o "paradigma", como él lo denomina, apelando para ello a las nociones kuhnianas. Así, a partir del examen de los trabajos de Luckmann, Berger, Wilson, Martin, Fenn, Parsons y Bellah, Tschannen señala que el "paradigma de la secularización" se sustenta en un núcleo analítico compuesto por tres conceptos clave (o "ejemplares"): diferenciación (el más relevante, a juicio de este autor), racionalización y mundanización. En torno a este núcleo

(80) Ritzer, George (2000). Teoría sociológica contemporánea. México: McGraw-Hill, p. 598.

(81) Ibíd.

(82) Tschannen, Olivier (1991). The secularization paradigm: A systematization. Journal for the Scientific Study of Religion, 30(4), 395-415. 
resulta factible ubicar una serie de otros ejemplares lógicamente subordinados, entre los cuales destacan la autonomización, privatización, generalización, pluralización y colapso de la visión de mundo.

La articulación de estos y otros procesos dentro del aludido paradigma, se expresa en los siguientes términos (83):

"En el curso de la historia, la religión llega a diferenciarse progresivamente de otros dominios de la vida social, emergiendo como un dominio institucional muy específico dentro de un nuevo tipo de estructura social constituido por diversas instituciones (educación, política, economía, etc.). Por ejemplo, la Iglesia y el Estado llegan a estar claramente diferenciados (diferenciación). Al mismo tiempo, las diversas instituciones no religiosas emergentes de este proceso de diferenciación comienzan a funcionar sobre la base de criterios racionalmente vinculados a sus funciones sociales específicas, e independientemente de cualquier control u orientación religiosos. Así, por ejemplo, la economía comienza a funcionar de una manera racional dictada por una lógica propia e inherente (racionalización). El impacto de estos procesos sobre la esfera religiosa lleva a esta última a perder parte de su especificidad, tornándose más mundana. Las organizaciones religiosas comienzan a responder a las necesidades psicológicas de sus miembros (mundanización)".

A juicio de Tschannen, de estos tres elementos, la diferenciación es la que presenta una mayor gama de consecuencias (84):

- Una de ellas es que "las otras instituciones se tornan autónomas respecto de la religión, la cual pierde así su poder de control y orientación social sobre el resto de la sociedad. -Por ejemplo- la educación se convierte en una empresa secular y autónoma (autonomización)".

- $\quad$ "Otra consecuencia es que la religión reorganiza sus fuerzas dentro de la sociedad, cambiando parcialmente su ubicación y función. Este movimiento se da en dos sentidos: por una parte, la religión se privatiza, lo que significa que cada individuo, en la medida en que se mueve constantemente entre diferentes esferas institucionales vinculadas a visiones de mundo mutuamente incompatibles, debe construir su propia interpretación de mundo, la cual implicaría un tipo de religión personalizada. Él puede crear su propio cóctel de devoción cristiana, budismo y creencia en la astrología (privatización). Por otra parte, la religión también se torna generalizada en el sentido de que se impregna de manera disfrazada en las instituciones seculares, manifestándose en la esfera económica mediante el "espíritu del capitalismo", o en la esfera política, como una "religión civil" (generalización)".

- Al propio tiempo, podemos observar la emergencia de un pluralismo religioso: "a medida que la autoridad política deja de reforzar la autoridad de la religión,

(83) Ibíd., pp. 400-401.

(84) Ibíd., pp. 401-402. 
el monopolio de la religión sucumbe, dando paso a una variedad de denominaciones en competencia, como es el caso de Estados Unidos (pluralización)".

- Finalmente, "como resultado de la pérdida de control social por parte de las iglesias, la práctica y afiliación religiosas decaen (declive en la práctica religiosa)".

Por su parte, el proceso de racionalización involucra dos consecuencias distin$\operatorname{tas}(85)$ :

- "En primer lugar, la visión racional del mundo está relacionada con la emergencia de la ciencia, la cual propone una visión de mundo que entra en competencia con la visión religiosa. Por ejemplo, el universo copernicano desplaza a la cosmología que visualizaba a la tierra como centro del universo (cientización)".

- "En segundo término, cuando esta interpretación científica y racional del mundo es aplicada a los asuntos humanos, acudimos a una "sociologización": un intento de determinar la vida social bajo patrones racionales, liberándola así de la influencia religiosa. Pasamos a confiar en los cientistas sociales y no en la invocación de la ética cristiana para resolver, por ejemplo, los problemas del crimen en las grandes ciudades (sociologización)".

De acuerdo a Tschannen, "dos elementos adicionales, colapso de la visión de mundo y no creencia, están situados en una posición intermedia y son manifestaciones del mismo fenómeno. A nivel societal, la visión religiosa del mundo pierde plausibilidad. Las teodiceas tradicionales pierden tanta credibilidad que incluso los teólogos reconocen la necesidad de su revisión (colapso de la visión de mundo). Este colapso está vinculado a un declive similar a nivel individual: muchos individuos ya no creen en Dios (no creencia). La pérdida de plausibilidad y no creencia pueden ser explicadas de dos maneras distintas: se les puede considerar como un resultado del superior poder explicativo de la ciencia (el colapso es una concomitante de la racionalización); o bien como el resultado de la pérdida de plausibilidad de las diferentes religiones, acarreada por su mutua lucha en una situación pluralista. En este último caso es la propia existencia de estas explicaciones del mundo mutuamente competitivas e incompatibles la que lleva al individuo a reflexionar y, finalmente, a rechazar a todas ellas (el colapso es una concomitante de la diferenciación)" (86).

En tanto un todo, "el paradigma descansa sobre dos amplias asunciones preliminares: una alude a que algunas de las raíces del proceso de secularización pueden encontrarse dentro de la propia religión (raíces religiosas); la otra es que la religión está, en alguna medida, inmanentemente vinculada a la condición humana (aunque no necesariamente a la naturaleza humana) y, por lo tanto, nunca desaparecerá completamente (no desaparición)" (87).

(85) Ibíd., p. 402.

(86) Ibíd., p. 402.

(87) Ibíd., p. 402. 
A juicio de nuestro autor, dos de los elementos arriba citados, el declive en la práctica religiosa y la sociologización, no están completamente contenidos dentro del paradigma. "Ello se debe a que estos elementos ya constituían bloques importantes en la construcción de los enfoques en competencia que precedieron al establecimiento del presente paradigma. La noción de que la secularización implica un declive de la práctica (una “descristianización”) constituyó una idea central de la "sociología religiosa" católica desarrollada en Europa entre los 30 y 60. Por su parte, la noción de sociologización es el elemento fundamental de los enfoques más positivistas del siglo XIX, como los desarrollados por Comte y Spencer, quienes en cierta medida buscaban reemplazar a la religión por la ciencia. Estos dos elementos constituyen los ejemplares más débiles -y de menor reconocimiento (académico)del paradigma" (88).

\section{LA SECULARIZACIÓN COMO PROCESO SOCIOEMPÍRICO}

Bien ha planteado Berger que, aun cuando sería erróneo considerar algunos hechos que afectan al mundo contemporáneo de la religión -tales como los movimientos de revitalización, o ciertos fundamentalismos- como prueba concluyente de la falsedad de todo aquello que se ha agrupado bajo el rótulo de "teoría de la secularización", se hace necesario reconocer que tanto los informes sobre la "muerte de Dios", como los relativos a los alcances de la racionalidad científica, han constituido, por decir lo menos, una exageración (89).

En este marco, como ya fue acusado, una discusión inacabada es la que se explaya en torno a la hipótesis de Berger en cuanto a que aquello que se ha denominado "la" teoría de la secularización sí ha funcionado, pero para un punto reducido del globo, cual es Europa occidental, la "isla secularizada" (90). Según este autor, en apoyo a esta afirmación parecieran estar los procesos de secularización de Inglaterra (madre de la revolución industrial y del capitalismo moderno), Suecia y Escandinavia en general, y, más recientemente, España e Italia. La situación particular de los países de Europa oriental quedaría aún en ciernes frente a las dubitativas postu-

(88) Ibíd., p. 402.

(89) Berger, Peter (1994). Una gloria lejana: La búsqueda de fe en una época de credulidad. Barcelona: Herder.

(90) Ibíd. Por cierto, una opinión muy diferente es la sustentada por Cox, para quien resulta evidente un renacimiento religioso de la Europa moderna y secular, cuyas causales podemos encontrar en la emergencia de movimientos desde la periferia (como el pentecostal-carismático), la rápida expansión del Islam a través de la inmigración, la fuerte competitividad que el pluralismo ha impuesto a las iglesias históricas, y la progresiva desinstitucionalización religiosa que promete formas de religiosidad difusa. Al respecto, véase:

Cox, Harvey (1993). Religión y política en Europa: Los nuevos debates de lo secular/sagrado y de lo público/privado. Historia y Fuente Oral, $N^{o} 10$.

En idéntico sentido, véanse:

Casanova, José (1994). Public religions in the modern world. Chicago: The University of Chicago Press.

Hervieu-Léger, Danièle (2003). Pour une sociologie des "modernités religieuses multiples": une autre approche de la "religion invisible" des sociétés européennes. Social Compass, 50(3), 287295 . 
laciones respecto a si la reciente importancia de la Iglesia Católica en Polonia o de la Iglesia Luterana en la antigua República Democrática de Alemania significan en la práctica una revitalización de la religión, o si este fenómeno se ha debido simplemente a la ausencia de otras instituciones capaces de proporcionar determinados espacios de libertad bajo lo que fueron los regímenes totalitarios del pasado reciente. A juicio de Berger, lo cierto es que más allá de esta isla secularizada, "el resto del mundo muestra el mismo fervor religioso de siempre, y quizás más. Primero que todo, encontramos la tenaz persistencia de las religiones tradicionales en vastas multitudes de personas en casi todas las regiones no occidentales: el este y el sudeste asiático (con la posible excepción del Japón), de una manera intensa en el sur de Asia, y en todo el mundo musulmán, el África subsahariana y América Latina" (91). Datos empíricos a nivel global, provenientes de sucesivos informes (entre 1994 y 1998) del World Values Survey (WVS) y del International Social Survey Programme (ISSP) (92), no vienen sino a confirmar estas apreciaciones, aun cuando, por regla general, los índices de creencia en Dios superan con creces a los de práctica u observancia religiosa (entendida como la asistencia a la iglesia al menos una vez por semana), situación que, para el particular caso de Europa, ha sido caracterizada por Davie (93) como “creer sin pertenecer". Incluso la hipótesis de Europa occidental como "isla secularizada" viene a ser confirmada por los datos de dichas fuentes (94), en conjunción con los del European Values Study de 1999/2000 (95), aun cuando, de acuerdo a ciertos estudios, "se ha observado" que los procesos de secularización ostentan distintas "velocidades" en los diversos países europeos, resaltando la República Checa y Francia como los más secularizados (baja creencia y baja práctica religiosas), mientras que Irlanda, Rumania y Polonia se hallarían en el polo opuesto (96).

Más allá de esta dimensión de fervor religioso, por cierto situable a nivel de creencias y prácticas religiosas, desde hace ya algún tiempo -y tal vez con particular énfasis durante estas últimas dos décadas- algunos desarrollos en el campo de la sociología de la religión nos vienen dando señales socioestructuralmente adversas a la noción de secularización, fundamentalmente en el ámbito de la interpenetración

(91) Berger, Peter (1994). Una gloria lejana: La búsqueda de fe en una época de credulidad. Barcelona: Herder, p. 47.

(92) Al respecto, véanse:

Lambert, Yves (1999). Religion in modernity as a new axial age: Secularization or new religious forms? Sociology of Religion, 60(3), 303-333.

Lehmann, Carla (2002). ¿Cuán religiosos somos los chilenos? Mapa de la religiosidad en 31 países. Estudios Públicos, 85, 21-40.

(93) Citado en Halman, Loek y Draulans, Veerle (2006). How secular is Europe? The British Journal of Sociology, 57(2), 263-288.

(94) Véase Dogan, Mattei (2002). Accelerated decline of religious beliefs in Europe. Comparative Sociology, 1(2), 127-149.

(95) Véase Halman, Loek y Draulans, Veerle (2006). How secular is Europe? The British Journal of Sociology, 57(2), 263-288.

(96) Ibíd. A juicio de estos autores, si bien ciertas variables (y sus eventuales conjugaciones) tales como el nivel de pluralismo religioso, desarrollo económico, grado de globalización, y confianza en las iglesias, parecen hallarse a la base de estas diferencias en las velocidades de secularización entre países europeos, las investigaciones empíricas hasta ahora desarrolladas no permiten realizar afirmaciones concluyentes al respecto. 
entre el subsistema religioso y el cultural, el económico, y, especialmente, el político. Bajo la concepción relativamente consensuada de que, contrariamente a lo que se suponía, la religión y las iglesias no se supeditaron finalmente a una mera relegación al ámbito privado, mientras la política (y el Estado) y la economía (mercado) consumaban para sí su supuesta primacía en la esfera pública, estas señales se han venido desarrollando con acentos diversos, pero mutuamente complementarios (97). Así, Robertson se ha explayado respecto de la -a su juicio, reciente- tendencia globalizada de interpenetración entre subsistemas religioso y político, a través de un proceso de doble vía caracterizado por una "politización de la religión" y una "religionización de la política", tomando para ello ejemplos desde los cinco continentes (98). Por otro lado, bajo el rótulo de "religión difusa", Cipriani ha resaltado el rol de la socialización temprana de ciertos valores religiosos (específicamente católicos) sobre el eventual disciplinamiento del voto en Italia (99). Para el caso de Bélgica, y bajo el prisma de una cuasi apología, Billiet ha mostrado cómo la membresía y participación en ciertas iglesias o asociaciones religiosas contribuye a la formación, mantención e incremento de capital social, así como a la promoción de valores democráticos (100).

Para el contexto latinoamericano, Bastian ha resaltado la "escasa secularización de la región" y la sedimentada vinculación entre ámbitos religioso y político a través de persistentes patrones de relación corporativista entre Estado e Iglesia Católica, actualmente reforzados por el pentecostalismo, pese a los frustrados esfuerzos modernizantes de los protestantismos históricos durante el siglo XIX y principios del XX (101). Asimismo, Meyer se ha referido al carácter brumoso de

(97) Véanse, al respecto:

Berger, Peter (1994). Una gloria lejana: La búsqueda de fe en una época de credulidad. Barcelona: Herder.

Berger, Peter (2001). La désécularisation du monde: Un point de vue global. En P. Berger (Dir.), Le réenchantement du monde (pp. 13-35). Paris: Bayard Éditions.

Casanova, José (1994). Public religions in the modern world. Chicago: The University of Chicago Press.

(98) Robertson, Roland (1989). Globalization, politics and religion. En J. Beckford y T. Luckmann (Edits.), The changing face of religion (pp. 10-23). London: International Sociological Association/Sage.

(99) Cipriani, Roberto (1989). "Difused religion" and new values in Italy. En J. Beckford y T. Luckmann (Edits.), The changing face of religion (pp. 24-48). London: International Sociological Association/Sage.

(100) Billiet, Jaak (1998). Social capital, religious-philosophical involvement and social integration in Belgium: An empirical investigation. En R. Laermans, B. Wilson \& J. Billiet (Edits.), Secularization and Social Integration (pp. 233-250). Louvain: Leuven University Press.

(101) Bastian, Jean Pierre (1995). El protestantismo en América Latina. En E. Dussel (Edit.), Resistencia y Esperanza: Historia del Pueblo Cristiano en América Latina y el Caribe (pp. 447-486). San José: DEI.

Bastian, Jean Pierre (1997). La mutación religiosa de América Latina: Para una sociología del cambio social en la modernidad periférica. México: Fondo de Cultura Económica.

Bastian, Jean Pierre (2001). Présentation: Apprendre à décentrer le regard sur la modernité religieuse. En J. P. Bastian (Dir.), La modernité religieuse en perspective comparée: Europe latineAmérique latine (pp. 5-11). Paris: Éditions Karthala.

Bastian, Jean Pierre (2001). Pentecôtismes latino-américains, logiques de marché et transnationalisation religieuse. En J. P. Bastian, F. Champion y K. Rousselet (Dirs.), La globalisation du religieux (pp. 99-111). Paris: L'Harmattan. 
las fronteras entre esferas religiosa y política, las que de manera inevitable se informan mutuamente, y en donde las acusaciones de injerencia religiosa en materias políticas muchas veces darían cuenta de una "concepción estrecha de la laicidad” (102). Dussel (103), Keogh (104) y Levine (105) nos muestran cómo la Iglesia Católica se ha mantenido como un perenne referente y actor de la esfera pública desde los inicios de la vida republicana en diversos países de la región, mientras Araneda (106), Dooner (107) y Smith (108) analizan lo propio para el caso específico de Chile. Stewart-Gambino destaca cómo las iglesias, y particularmente la Iglesia Católica, han jugado un rol mediador primordial en los procesos de pacificación en Centroamérica; en los intentos de diálogo entre las fuerzas de guerrilla y autoridades de gobierno en países como Perú, México y Colombia; e incluso en procesos de negociación, en este último país, entre gobierno y grupos de narcotráfico (109).

En un ámbito paralelo, se ha documentado una variada gama de fenómenos de interpenetración evangélica con el subsistema político en América Latina, que modificaría incluso las convencionales y estereotipadas visiones sociológicas de estos sectores como supuestamente apolíticos (Cleary, 1997; Dodson, 1997; Smith, 1998; Stoll, 1993; Stewart-Gambino y Wilson, 1997). Así, para el caso de Brasil, Freston (110) e Ireland (111) nos muestran de manera sistemática las proporciones de la representación parlamentaria evangélica y la construcción de un proyecto evangélico corporativo

(102) Meyer, Jean (2000). El Estado laico: Trayectoria histórica y significado presente. En R. Blancarte (Comp.), Laicidad y valores en un Estado democrático (pp. 141-152). México: Secretaría de Gobernación, Subsecretaría de Asuntos Religiosos/El Colegio de México.

(103) Dussel, Enrique (1995). La Iglesia en el proceso de la organización nacional y de los Estados en América Latina (1830-1880). En E. Dussel (Edit.), Resistencia y Esperanza: Historia del Pueblo Cristiano en América Latina y el Caribe (pp. 159-172). San José: DEI.

Dussel, Enrique (1995). La Iglesia a partir de 1972. En E. Dussel (Edit.), Resistencia y Esperanza: Historia del Pueblo Cristiano en América Latina y el Caribe (pp. 253-289). San José: DEI.

(104) Keogh, Dermot (1990). Catholicism in Latin America: Conclusions and perspectives. En D. Keogh (Ed.), Church and politics in Latin America (pp. 398-403). London: The Macmillan Press.

(105) Levine, Daniel (1990). The Catholic Church and politics in Latin America: Basic trends and likely futures. En D. Keogh (Ed.), Church and politics in Latin America (pp. 25-48). London: The Macmillan Press.

(106) Araneda, Fidel (1988). El clero en el acontecer político chileno. Santiago: Emisión.

(107) Dooner, Patricio (1986). La iglesia: Un actor político peculiar. Estudios Sociales, 50, 99-114.

(108) Smith, Brian (1982). The Church and politics in Chile. Princeton, N.J.: Princeton University Press.

Smith, Brian (1990). The Catholic Church and politics in Chile. En D. Keogh (Ed.), Church and politics in Latin America (pp. 321-343). London: The Macmillan Press.

(109) Stewart-Gambino, Hannah (1992). Introduction: New game, new rules. En E. Cleary y H. Stewart-Gambino (Eds.), Conflict and competition: The Latin American Church in a changing environment (pp. 1-19). Colorado: Lynne Rienner Publishers.

(110) Freston, Paul (1991). Brasil: En busca de un proyecto evangélico corporativo. En R. Padilla (Comp.), De la marginación al compromiso: Los evangélicos y la política en América Latina (pp. 21-36). Buenos Aires: Fraternidad Teológica Latinoamericana.

Freston, Paul (1993). Brother votes for brother: The new politics of protestantism in Brazil. En V. Garrard-Burnet y D. Stoll (Eds.), Rethinking protestantism in Latin America (pp.45-65). Philadelphia: Temple University Press.

(111) Ireland, Rowan (1997). Pentecostalism, conversions, and politics in Brazil. En E. Cleary and H. Stewart-Gambino (Eds.), Power, politics, and pentecostals in Latin America (pp. 123-138). Boulder: Westview Press. 
desde la década de los 80; mientras Carranza (112) y Williams (113) han analizado la progresiva relevancia electoral del pentecostalismo en El Salvador. De la misma manera, han sido profusamente documentados los procesos de legitimación de regímenes autoritarios por parte de algunos sectores evangélicos en Guatemala (114) y en Chile (115); en tanto que Arroyo y Paredes (116) y Martin (117) han analizado la importancia del soporte parlamentario y propagandístico de ciertos sectores evangélicos peruanos en lo que fueron las victorias electorales de Fujimori.

(112) Carranza, Mardoqueo (1991). El Salvador: Ingreso a un mundo desconocido. En R. Padilla (Comp.), De la marginación al compromiso: Los evangélicos y la política en América Latina (pp. 53-60). Buenos Aires: Fraternidad Teológica Latinoamericana.

(113) Williams, Philip (1997). The sound of tambourines: The politics of Pentecostal growth in El Salvador. En E. Cleary and H. Stewart-Gambino (Eds.), Power, politics, and pentecostals in Latin America (pp. 179-200). Boulder: Westview Press.

(114) Bastian, Jean Pierre (1990). Historia del protestantismo en América Latina. México: CUPSA. Bastian, Jean Pierre (1997). La mutación religiosa de América Latina: Para una sociología del cambio social en la modernidad periférica. México: Fondo de Cultura Económica.

Martin, David (1990). Tongues of fire: The explosion of Protestantism in Latin America. Oxford: Basil Blackwell.

Martin, David (1991). Otro tipo de revolución cultural: El protestantismo radical en Latinoamérica. Estudios Públicos, 44, 39-62.

Stoll, David (1990). Is Latin America turning protestant? Berkeley: University of California Press.

Wilson, Everett (1997). Guatemalan pentecostals: Something of their own. En E. Cleary and H. Stewart-Gambino (Eds.), Power, politics, and pentecostals in Latin America (pp. 139-162). Boulder: Westview Press.

(115) Cleary, Edward y Sepúlveda, Juan (1997). Chilean pentecostalism: Coming of age. En E. Cleary and H. Stewart-Gambino (Eds.), Power, politics, and pentecostals in Latin America (pp. 97-122). Boulder: Westview Press.

Donoso-Maluf, Francisco (1996). Comunitarización competitiva: Auge de la Iglesia Metodista Pentecostal de Chile. Tesis de Maestría en Ciencias Sociales, FLACSO, Ciudad de México, México.

Donoso-Maluf, Francisco (1998a). Comunitarización competitiva: Auge de la Iglesia Metodista Pentecostal de Chile. Perfiles Latinoamericanos, 13, 229-258.

Donoso-Maluf, Francisco (1998b). Comunitarización competitiva: Nuevas dimensiones analíticas para las actuales facetas de un viejo pentecostalismo. Logos, 8, 183-197.

Kamsteeg, Frans (1998). Prophetic pentecostalism in Chile. A case study on religion and development policy. Lanham: The Scarecrow Press.

Kamsteeg, Frans (1999). Pentecostalism and political awakening in Pinochet s Chile and beyond. En Ch. Smith y J. Prokopy (Eds.),

Latin American religion in motion (pp. 187-204). New York: Routledge.

Lagos, Humberto (1978). La libertad religiosa en Chile, los evangélicos y el gobierno militar, Tomos 1-3. Santiago: Vicaría de la Solidaridad/Arzobispado de Santiago/U.N.E.L.A.M.

Lagos, Humberto (1988). Crisis de la esperanza. Religión y autoritarismo en Chile. Santiago: Presor/Lar.

Lagos, Humberto (1991). Chile: ¿Legitimidad "metasocial” o afirmación del Dios de la vida? En R. Padilla (Comp.), De la marginación al compromiso: Los evangélicos y la política en América Latina (pp. 37-51). Buenos Aires: Fraternidad Teológica Latinoamericana.

Sepúlveda, Juan (1996). Reinterpreting Chilean pentecostalism. Social Compass, 43(3), 299-318. Sepúlveda, Juan (1999). De peregrinos a ciudadanos: Breve historia del cristianismo evangélico en Chile. Santiago: Fundación Konrad Adenauer/Facultad Evangélica de Teología, Comunidad Teológica Evangélica.

(116) Arroyo, Víctor y Paredes, Tito (1991). Perú: Los evangélicos y el "fenómeno Fujimori”. En R. Padilla (Comp.), De la marginación al compromiso: Los evangélicos y la política en América Latina (pp. 89-101). Buenos Aires: Fraternidad Teológica Latinoamericana.

(117) Martin, David (1991). Otro tipo de revolución cultural: El protestantismo radical en Latinoamérica. Estudios Públicos, 44, 39-62. 
Las problemáticas derivadas de esta clase de manifestaciones poseen estribaciones en laberintos explicativos que no terminan de dejar en claro si ellas obedecen de manera primordial a cambios recientemente emergentes en las relaciones de la religión con otros subsistemas sociales, a errores o sesgos eurocentristas de los autores de países desarrollados que lideraron las nociones y teorizaciones en torno a los procesos de secularización y laicización institucional, o a la conjugación de ambas clases de factores (118). Lo cierto es que la concurrencia de esta diversidad de "observables" parece poner en jaque no solo a "la Teoría de la Secularización", sino a la noción misma de secularización como categoría de observación construida/ sustentada por "dicha" teoría. En tanto tal, y exceptuando el caso de Europa occidental, la secularización como supuesto proceso sociohistórico lineal y progresivo no logra escapar de la suerte corrida tanto por el concepto, como por las teorías y el paradigma de la secularización: el enfrentamiento de una situación de anomalíascrisis.

\section{LA SECULARIZACIÓN COMO DOGMA O "FE"}

Uno de los postulados fundamentales de Durkheim es que las dinámicas religiosas son capaces de reproducir su sentido en esferas y actividades profanas (119). Incluimos, pues, esta breve sección, fundamentalmente para subrayar una situación que salta a la vista en algunos textos que hemos consultado: nos referimos a la cuasi durkheimiana noción de que la secularización, y "la" teoría de la secularización, parecieron haber llegado a ostentar un carácter alusivo a una especie de dogma o fe: La fe en el avance de la razón, la fe en el avance de la secularización.

Lo anterior se desprende del tipo de tratamiento discursivo más o menos irónico conferido a la discusión en torno a la vigencia/obsolescencia de las teorías de la secularización. Lo curioso, no obstante, es que dicho tratamiento es utilizado lo mismo por algunos de los más férreos defensores y detractores de las teorías de la secularización. Así, por ejemplo, Mason (120) nos describe el escenario de este debate bajo la imagen de una teoría de la secularización transformada en una suerte de credo, en donde se enfrentan los "creyentes" - aferrados al viejo credo- contra un batallón compuesto por los "conversos" a la teoría de la desecularización de Berger, más los "acólitos" de Stark y del modelo de economía religiosa. De hecho, lo anterior no resulta casual en el contexto de un artículo en el que Mason intenta demostrar la vigencia del viejo credo paradigmático de la secularización. Es más, resulta bastante pintoresca la peculiar incursión que allí hará dicho autor por las boscosas latitudes del "honor intelectual" en que se forjó Berger, como medio explicativo para intentar comprender las neodeclaraciones teóricas de este último acerca de su deserción del viejo credo-paradigma.

(118) Al respecto, véase Blancarte, Roberto (2001). Laicidad y secularización en México. Estudios Sociológicos, XIX (57), 843-855.

(119) Durkheim, Emilio (1912/2000). Las formas elementales de la vida religiosa. México: Colofón.

(120) Mason, Michael (2002, Julio). Secularisation is alive and well-and living in Australia. Paper presented at the World Congress of Sociology; Brisbane, Australia. 
Por su parte, Casanova, que inicia el primer capítulo de su más conocido trabajo con la interrogante “¿Quién cree todavía en el mito de la secularización?”, utilizará una terminología similar en el seno de este debate. Así, afirmará que "todavía quedan algunos 'viejos creyentes', tales como Bryan Wilson y Karel Dobbelaere, quienes insisten en que la teoría de la secularización aún goza de gran valor explicativo" (121).

Con todo, más allá del grado de fe que podamos (man)tener hoy en la secularización, todo parece indicar que este tinte del debate alude a una suerte de "secularización de la secularización" que, en tanto tal, viene sintomáticamente a erosionar el carácter de fe/dogma que esta albergara nítidamente hasta los 60 , con ciertas extensiones todavía en pie hasta los 80 .

\section{DISCUSIÓN}

- El concepto de secularización encarna algunas tensiones cruciales e inherentes. Por una parte, se trata de un término que ha experimentado migraciones por diversos dominios, incrementando recursivamente con ello su complejidad, acentos y polisemia. Así, como ha afirmado Luhmann, el concepto de secularización tiene sus orígenes en operaciones de distinción entre lo religioso y lo no religioso realizadas desde el propio subsistema religioso, y es en ese marco que cobra relevancia y sentido. Según dicho autor, cuando la distinción es realizada desde una perspectiva social más amplia, es el concepto de diferenciación, y no el de secularización, el que guarda relevancia (122). Pese a lo anterior, a nuestro juicio, resulta evidente que en su trayecto histórico el concepto de secularización pasará a ser apropiado implícita y/o explícitamente como código de diversos subsistemas, dando pie, incluso, a su tipificación como "doctrina" o "ideología", más que como una -ingenuamente asumida- herramienta "científica", analítica y valóricamente neutral (123).

No obstante, acaso el mayor problema con el concepto de secularización ha sido el de su evolutiva hipertrofia semántica como "mecanismo de defensa" frente a ciertas desconfirmaciones empíricas de la tesis, teoría y/o paradigma de la secularización. Lo anterior ha derivado en una amplia pluralización de significados $-\mathrm{o}$ multidimensionalización del concepto, como lo muestra el caso de Dobbelaere- (124) a fin de mantener en pie el castillo, pero ello al precio de complejizar cada vez más el proceso de debate en torno al "fenómeno".

- En conformidad con lo anterior, creemos que el viejo y fallido intento de asociación entre modernidad y secularización no logra ser convincentemente corregido,

(121) Casanova, José (1994). Public religions in the modern world. Chicago: The University of Chicago Press, p. 11.

(122) Laermans, Rudi y Verschraegen, Gert (2001). “The late Niklas Luhmann” on religion: An overview. Social Compass, 48(1), 7-20.

(123) Al respecto, véase Swatos, William Jr. y Christiano, Kevin (1999). Secularization theory: The course of a concept. Sociology of Religion, 60(3), 209-228.

(124) Dobbelaere, Karel (1981/1994). Secularización: Un concepto multi-dimensional. México: Universidad Iberoamericana. 
superado o reformulado ni con el de postmodernidad/postsecularización, ni con ninguna de las sintomáticas cirugías que han venido siendo recursivamente aplicadas a ambos lados del binomio para los salvíficos fines de lograr elasticidad semántica (hipermodernidad, ultramodernidad, desecularización, neosecularización, etc.). De mayor franqueza teórica y conceptual pareciera ser el asumir que la modernidad no acabó del todo con elementos propios del mundo tradicional, manteniendo con este ciertos patrones de coexistencia -con francas consecuencias para la relación religión/sociedad-, cuestión que para el particular caso de América Latina ha venido siendo acusada desde hace ya varias décadas, bajo distintos lentes y énfasis, por figuras como Medina Echavarría (125), Lalive D’Epinay (126), Morandé (127), Brunner (128) o García Canclini (129).

Bajo el mismo impulso, y eximiéndonos de todo intento de colaborar a la hipertrofia del concepto de secularización, sería también de honestidad el mantener su acepción original (esto es, como declive de la religión a nivel individual y socioestructural), y asumir que las profecías de época acerca de su itinerario (hasta sus últimas consecuencias) a nivel global, simplemente fallaron. Tal como ha subrayado Berger (130), lo anterior no significa negar que la religión y las organizaciones religiosas se hayan modernizado, estructurando procesos de racionalización, diferenciación y pluralización; pero ello en caso alguno alude a un camino forzosamente conducente a la secularización, sino más bien a un proceso de horizontalización de la religión respecto de otros subsistemas y organizaciones sociales, con los cuales, en muchos casos, entrará a competir en tanto fuente de legitimación social y de dotación de sentido. Es en este marco que, a nuestro juicio, la religión nunca habrá de carecer de un locus social y de una fundamentación funcional.

- De acuerdo a lo anterior, y en función de los antecedentes empíricos disponibles, creemos que -exceptuando el caso de Europa occidental- solo resulta factible referirnos a la "secularización" como una noción de época mediante la cual fue imaginado el futuro de la religión desde las ciencias sociales y algunas corrientes teológicas, y no como una categoría teórica/conceptual que nos permita abordar hoy, de manera convincente, las expresiones, estatus y vinculaciones de la religión con otros subsistemas sociales. En otras palabras, a nuestro juicio, el concepto y "la" teoría de la secularización resultan ser hoy descriptivamente estériles y de escasa utilidad analítica. Ello no impide, no obstante, rescatar ciertos elementos parciales de algunas teorías de la secularización que, a nuestro juicio,

(125) Medina Echavarría, José (1964). Consideraciones sociológicas sobre el desarrollo económico de América Latina. Buenos Aires: Solar-Hachette.

(126) Lalive D’Epinay, Christian (1968). El refugio de las masas: Estudio sociológico del protestantismo en Chile. Santiago: Editorial del Pacífico.

(127) Morandé, Pedro (1984). Cultura y modernización en América Latina. Santiago: Pontificia Universidad Católica de Chile.

(128) Brunner, José Joaquín (1992). América Latina en la encrucijada de la modernidad. Documento de Trabajo, Serie Educación y Cultura, 22. Santiago: FLACSO.

(129) García Canclini, Néstor (1989/2002). Culturas híbridas: Estrategias para entrar y salir de la modernidad. México: Grijalbo.

(130) Berger, Peter (1994). Una gloria lejana: La búsqueda de fe en una época de credulidad. Barcelona: Herder. 
sí resultan ser herramientas valiosas y productivas para abordar y explicar ya no la secularización, sino ciertos cambios diacrónicos y manifestaciones sociales actuales de la religión. Entre esos elementos de valor, sobresalen los rótulos de diferenciación social, racionalización, pluralismo, competitividad y privatización, aun cuando, a nuestro juicio, todos ellos habrán de requerir de matices y precisiones a la hora de analizar la naturaleza de los procesos sociorreligiosos en contextos específicos, como el latinoamericano.

- Lo que habitualmente se ha denominado bajo el rótulo de "La Teoría de la Secularización" debe en realidad ser entendido como "Paradigma de la Secularización". Ello no constituye un mero juego de palabras, sino que nos permite insertar el actual debate en torno a los problemas que viene enfrentando un determinado marco de investigación, para abrir la eventual posibilidad de pasar a otro nuevo, dotado de herramientas analíticas factibles de dar respuestas convincentes para los fenómenos empíricos que hoy estamos presenciando en la arena sociorreligiosa y en su interpenetración con otros subsistemas sociales. En tanto tal, todo parece indicar que el aludido paradigma de la secularización se encuentra actualmente dando muestras de un proceso de "crisis", de acuerdo a la ya abordada jerga kuhniana. Dichas deficiencias parecen derivar de un set de fenómenos empíricos de diversa naturaleza (económicos, socioculturales y, sobre todo, políticos) que no calzan con -ni logran ser convincentemente explicados por- los postulados de la secularización.

- Las aludidas deficiencias del paradigma de la secularización parecen derivar, al menos en parte, de tres aspectos:

a) La ya acusada asociación modernidad/secularización.

b) La diacrónica mantención de una subyacente predisposición iluminista -políticamente funcional en sus momentos fundacionales- a relegar a la religión a un rol imperiosamente ajeno a la esfera pública y, en sus expresiones más extremas, con una clara sentencia de defunción, de acuerdo a la asunción de un progresivo vacío funcional para la religión dentro de un orden social secular crecientemente dominado por una racionalidad técnico-científica.

c) La pretensión de validez universal de las premisas de la secularización, no obstante su pronunciado y comprobado sesgo eurocéntrico.

- De acuerdo a todo lo anterior, un eventual cambio de "paradigma de la secularización” implicaría, desde la perspectiva kuhniana, al menos dos posibilidades para los cuadros en combate: 1) La de los autores que se aferran a la vigencia del paradigma anterior -entre los cuales Wilson pareciera constituir una figura emblemática-, optando incluso por dotar de nuevas elasticidades semánticas al concepto de secularización - como lo muestran los casos de Bruce, Mason y Dobbelaere-; y 2) La de aquellos que habrán de adscribirse a un nuevo paradigma (Berger). A juicio del propio Kuhn (131), si un eventual nuevo paradigma alcanza un triunfo contundente, el panorama se presentará bastante desolador para los autores que adscriben a la posición 1), redundando seguramente en un aislamiento teórico e intelectual en relación a sus respectivas comunidades

(131) Kuhn, Thomas (1962/2000). La estructura de las revoluciones científicas. México: Fondo de Cultura Económica. 
científicas/disciplinares; cuestión que, por cierto, ya se ha hecho relativamente patente a la luz de lo observable en la literatura de estas últimas décadas en torno al problema de la secularización.

- Difícil resulta el esgrimir o imaginar desde aquí, con cierta precisión, cómo debiera estructurarse teórica y analíticamente un eventual nuevo paradigma (dotado, seguramente, de un nuevo nombre y/o de un nuevo concepto). No obstante, por razones ya de sobra explicitadas en el presente trabajo, creemos que en su seno los conceptos de diferenciación/desdiferenciación, pluralización y competitividad debieran ostentar un estatus privilegiado.

- La centralidad analítica de los procesos de diferenciación social/funcional no debiera limitar la viabilidad de incluir fenómenos eventualmente asociados a esta, como los de desdiferenciación e interpenetración sistémica. El no hacerlo, nos sumergiría nuevamente en una peligrosa concepción lineal respecto de la función y locus social de la religión. A nuestro juicio, es justamente a partir de nuestra atención y examen de las zigzagueantes expresiones de diferenciación y desdiferenciación social en determinados contextos, que podremos entender bajo ópticas de mayor calibre las modalidades de interpenetración de la religión con otros subsistemas sociales y, al mismo tiempo, identificar y comprender los límites, expresiones y/o remisiones de los propios procesos de diferenciación de la religión en el mundo contemporáneo.

\title{
RESUMEN
}

El presente artículo aborda el tópico de la secularización como concepto, tesis, teoría, paradigma, proceso socioempírico y dogma/fe, intentando dar cuenta de los profusos debates registrados en el marco de las ciencias sociales de los últimos 20 años en torno a la vitalidad/ agonía y porvenir de sus postulados en cada una de dichas acepciones. Asumiendo la excepcionalidad de Europa occidental, se destaca y discute una serie de desconfirmaciones empíricas -con particular atención en América Latina- que parecen venir minando lo que fuera el "paradigma de la secularización", generando una interesante dinámica entre autores críticos y defensores, así como un conjunto de interrogantes en torno al futuro de la noción de secularización.

Palabras clave: Secularización, religión, modernidad, diferenciación funcional, paradigma.

\begin{abstract}
This article examines the topic of secularization as concept, thesis, theory, paradigm, socio-empirical process and dogma/faith, thus attempting to revise the profusion of debates which have taken place within the framework of social sciences during the last 20 years about the vitality/agony and future of these many faces of secularization. Presuming that Western Europe is an exception, Unlike the exceptional case of Western Europe, a series of empirical disconfirmations is highlighted and discussed -with particular attention paid to Latin Americathat seem to undermine what has been the "paradigm of secularization". This generated and interesting dynamic between the critics and defending authors of such a paradigm, as well as a set of questions about the future of the secularization.
\end{abstract}

Key words: Secularization, religion, modernity, functional differentiation, paradigm. 